\title{
P-Arylation of Dialkyl Phosphites and Secondary Phosphine Oxides with Arynes
}

\author{
Qian Chen, * Xinxing Yan, Zhiyun Du, Kun Zhang, and Chunxiao Wen \\ School of Chemical Engineering and Light Industry, Guangdong University of \\ Technology, Guangzhou, Guangdong 510006, China \\ *E-mail: qianchen@gdut.edu.cn
}

\section{SUPPORTING INFORMATION}

\section{Content:}

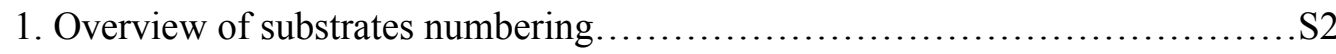

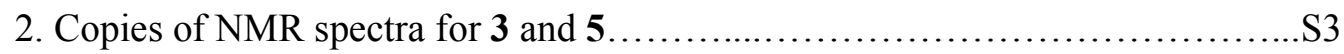

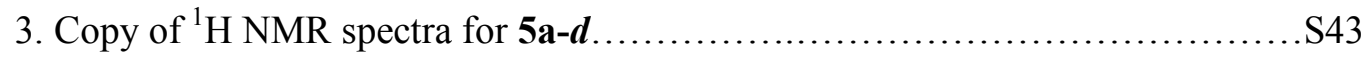




\section{Overview of substrates numbering}

\section{Aryne precursors}
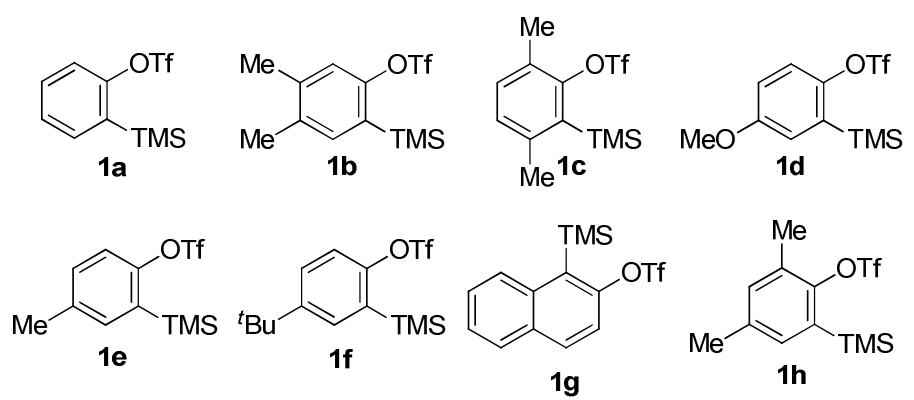

\section{Dialkyl phosphites}

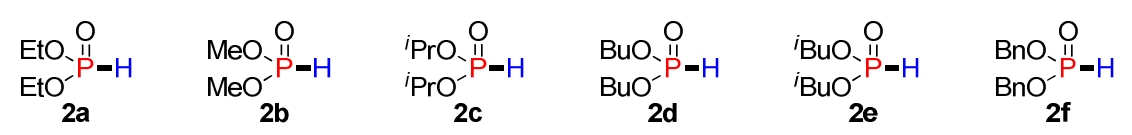

Secondary phosphine oxides

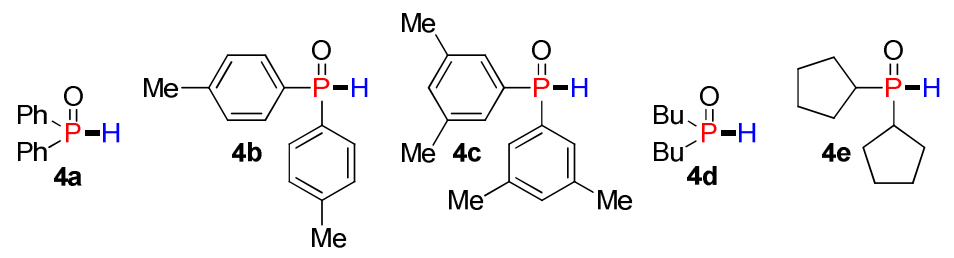


2. Copies of NMR spectra for 3 and $5\left({ }^{1} \mathrm{H},{ }^{13} \mathrm{C}\right.$, and $\left.{ }^{13} \mathrm{P}\right)$.
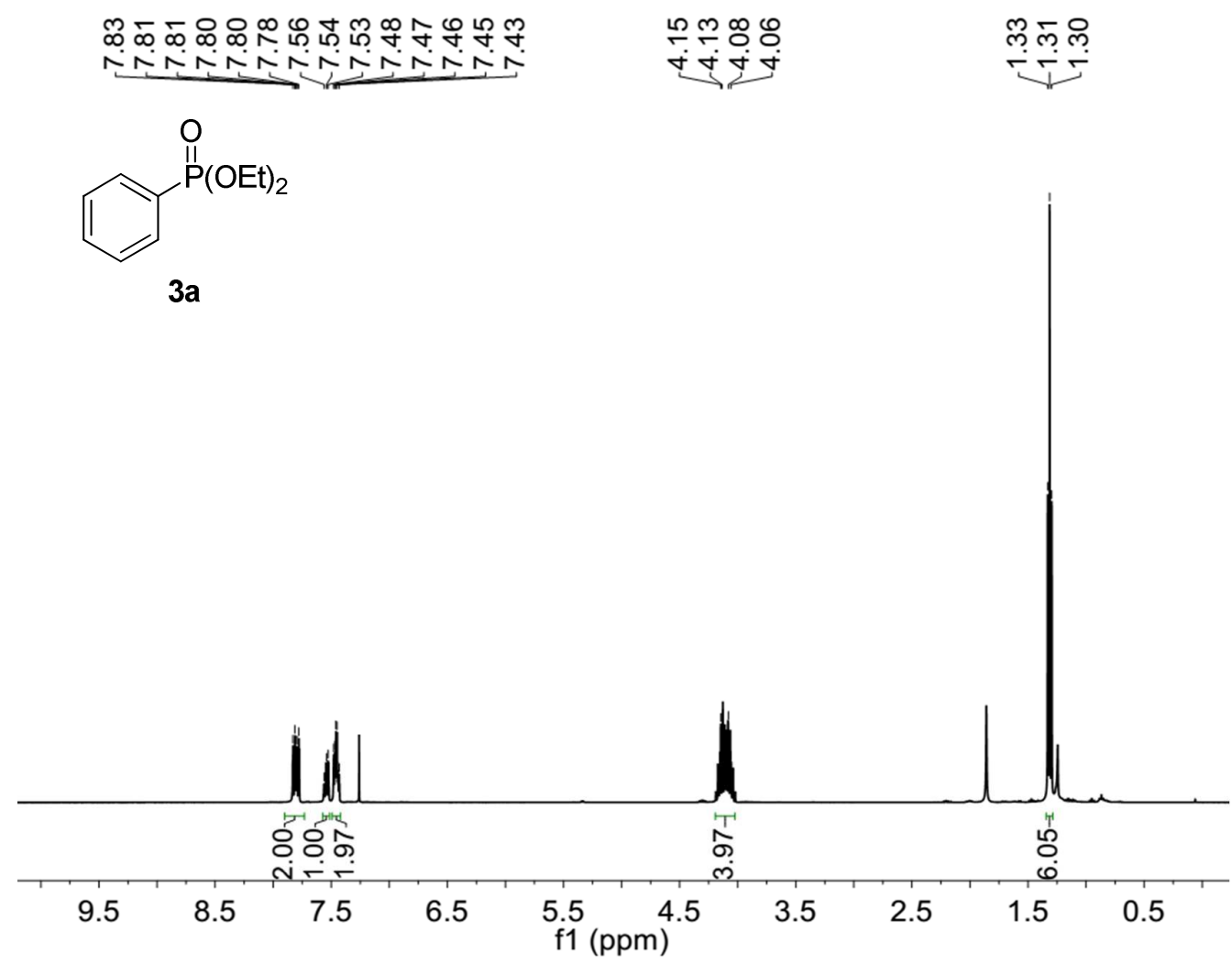

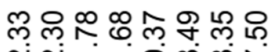

กิ่

을 잉<smiles>CCOP(=O)(OCC)c1ccccc1</smiles>

$3 a$
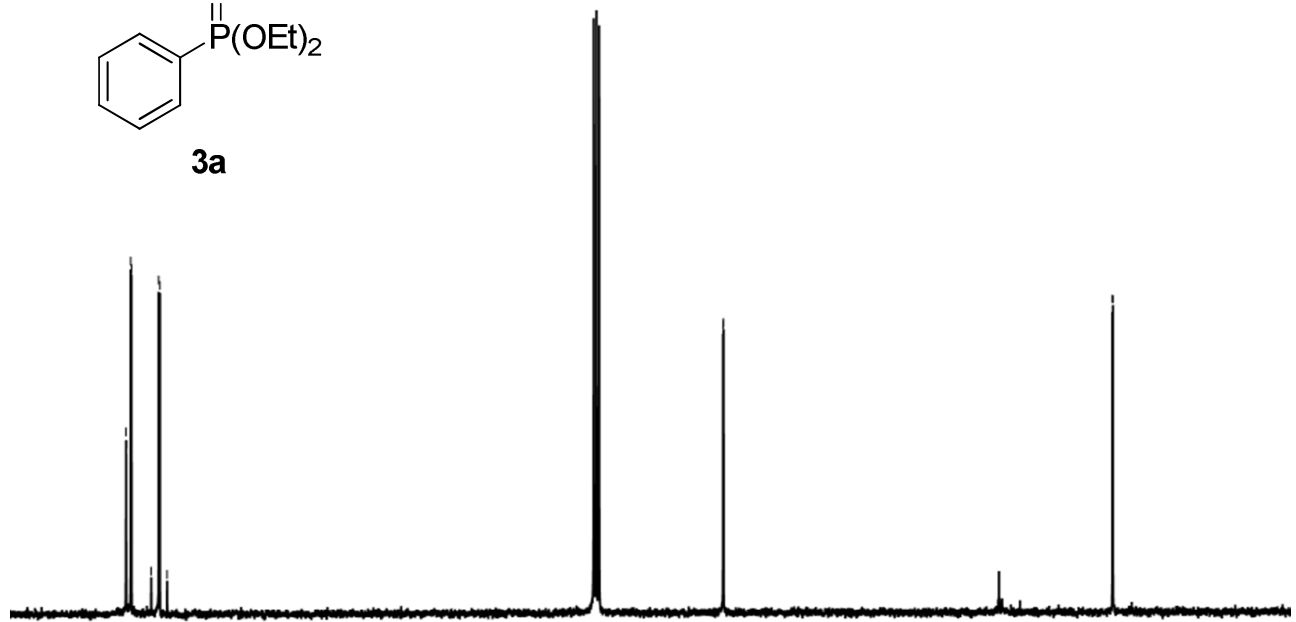

130

110

$\begin{array}{llc}90 & 80 & 70 \\ & \mathrm{f} 1 & (\mathrm{ppm})\end{array}$

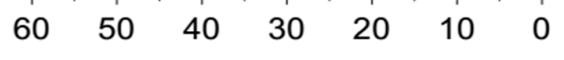



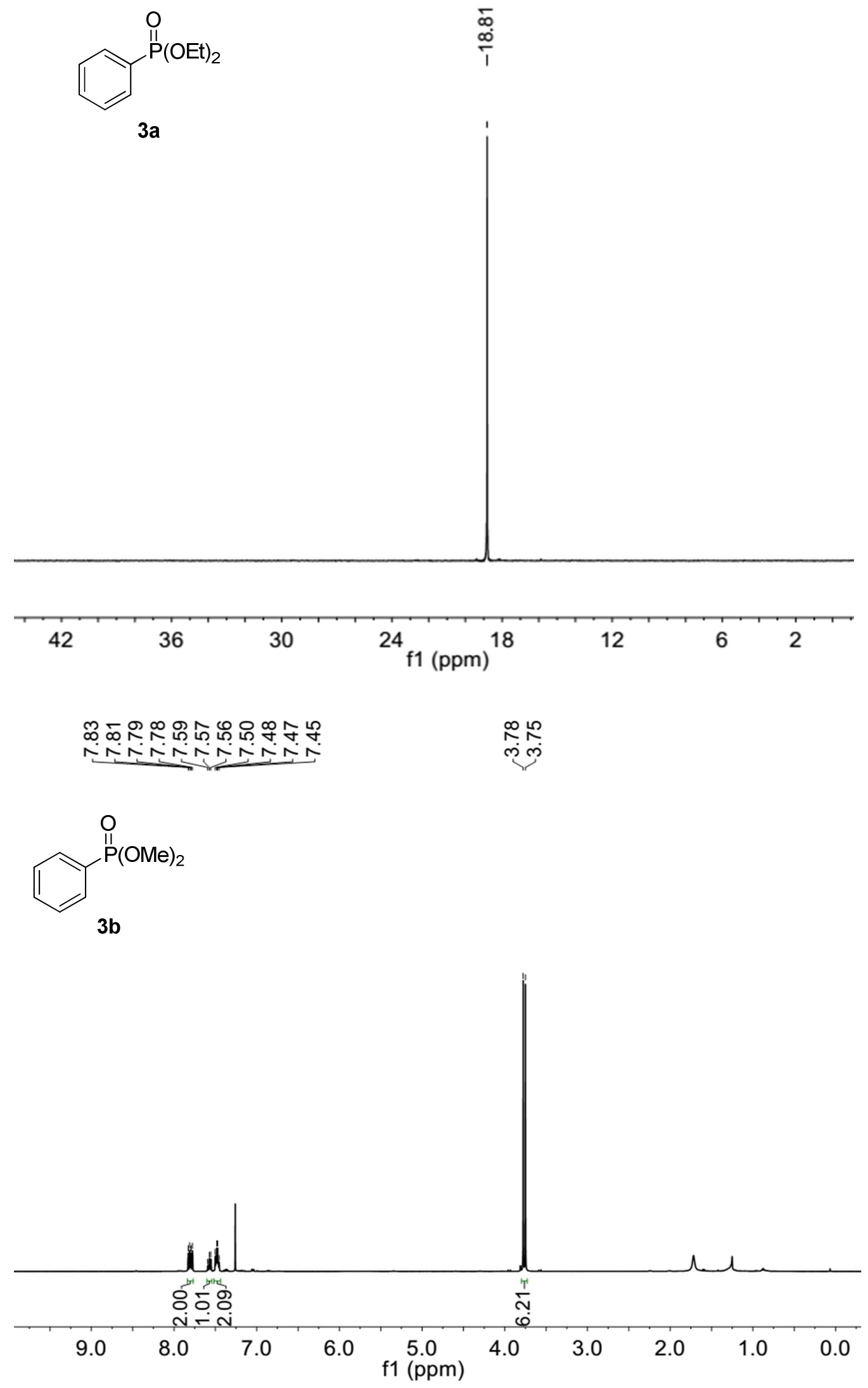

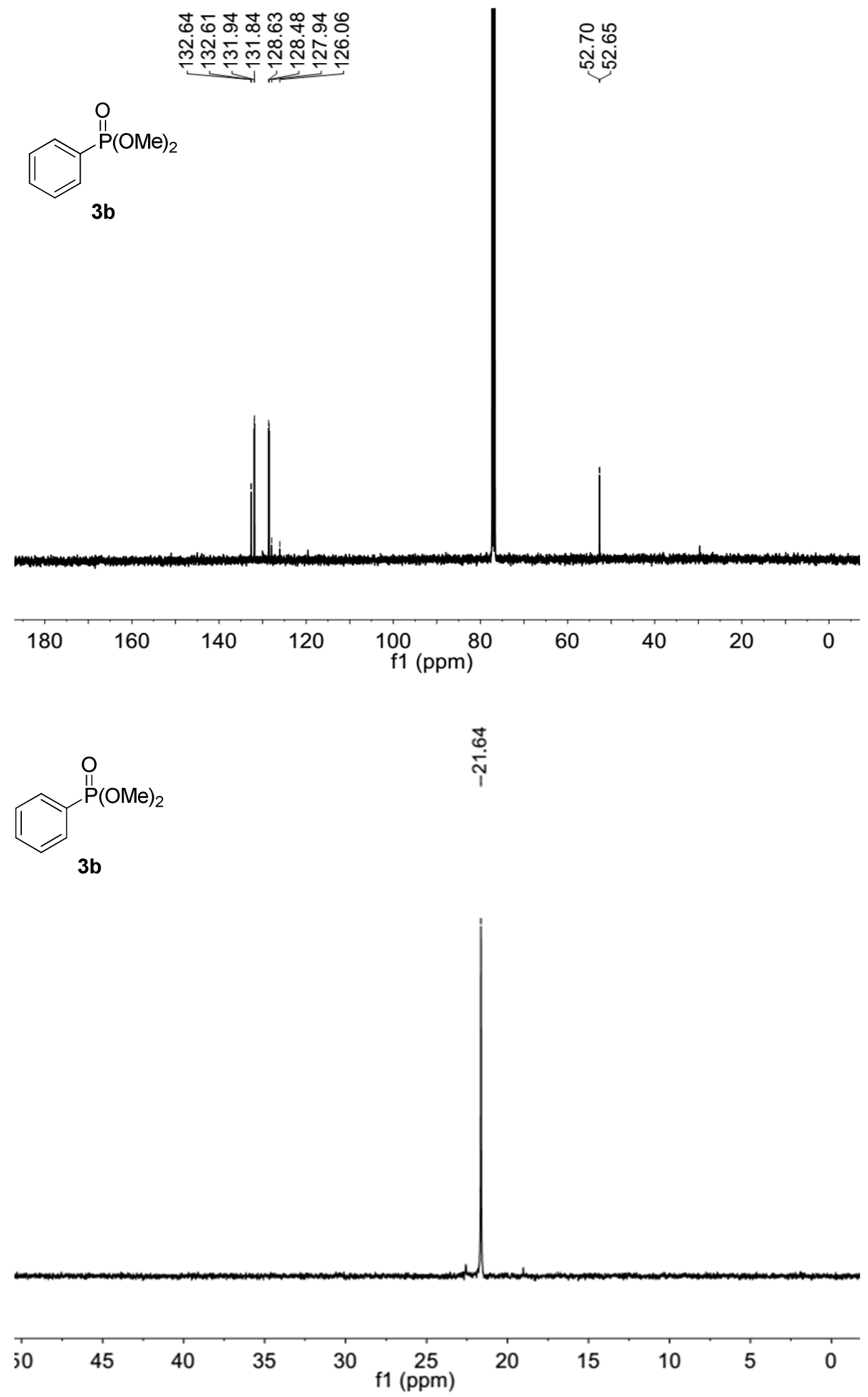
ז

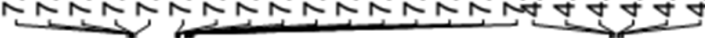
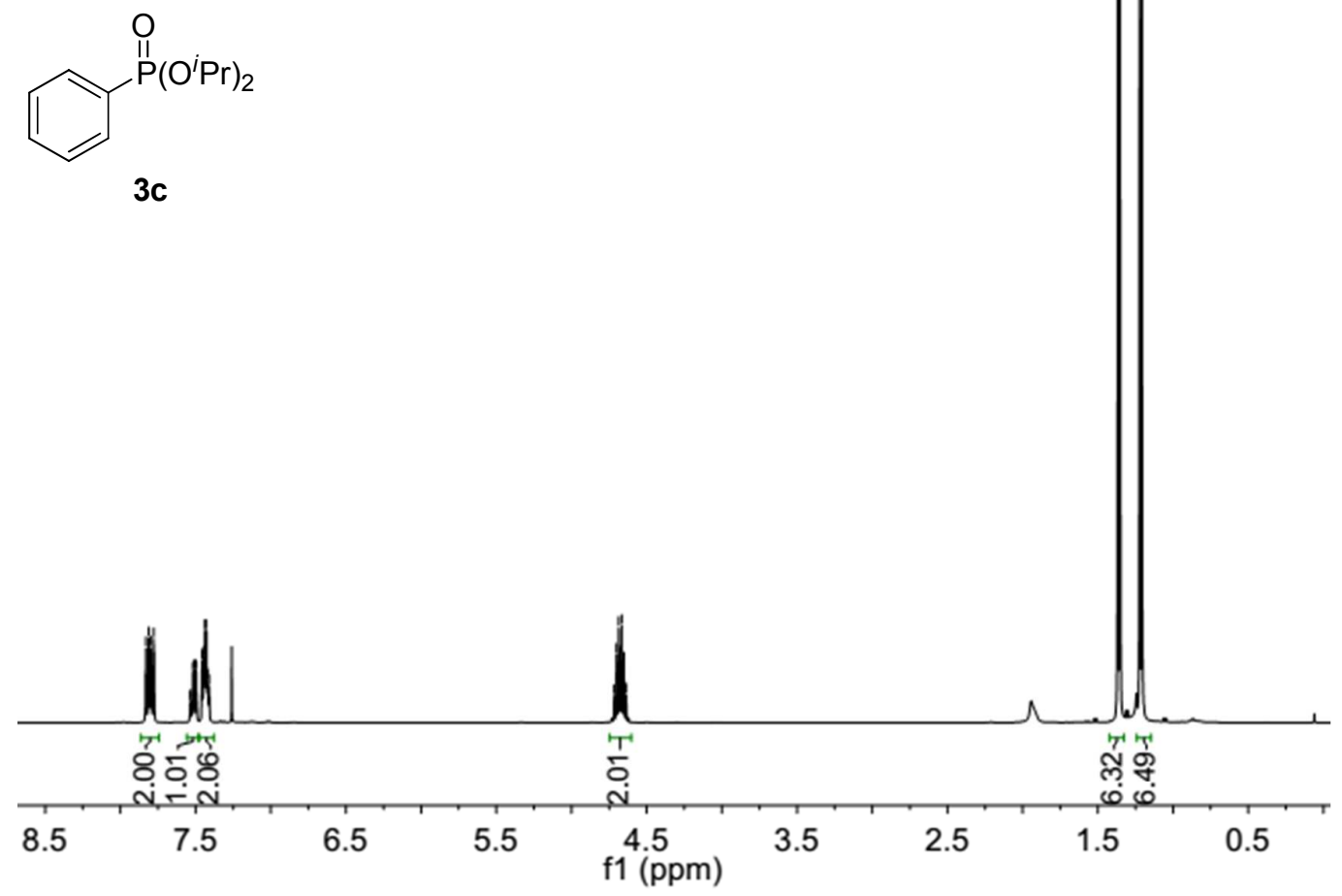

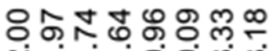

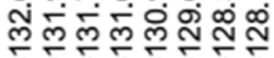

용

८ัญำ

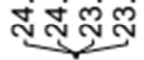<smiles>O=[Po]([O-])c1ccccc1</smiles>

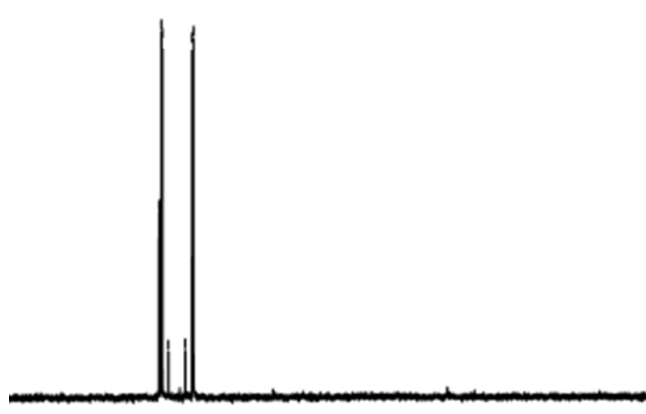

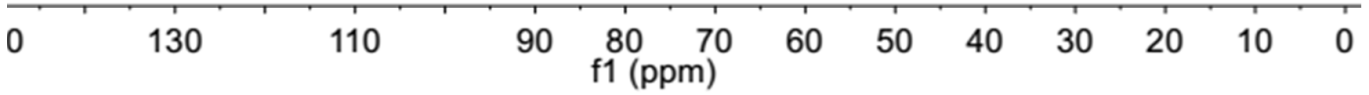



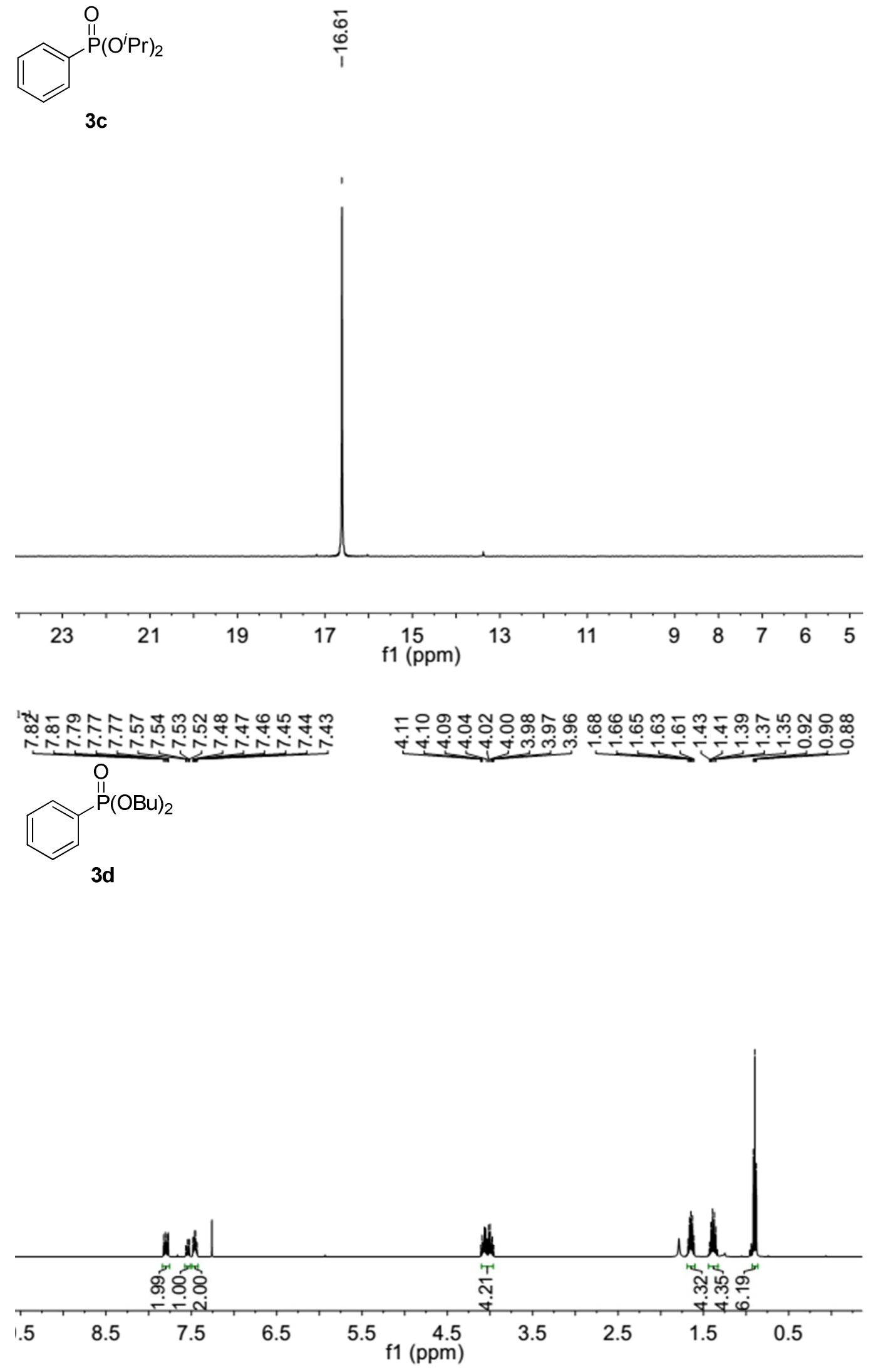

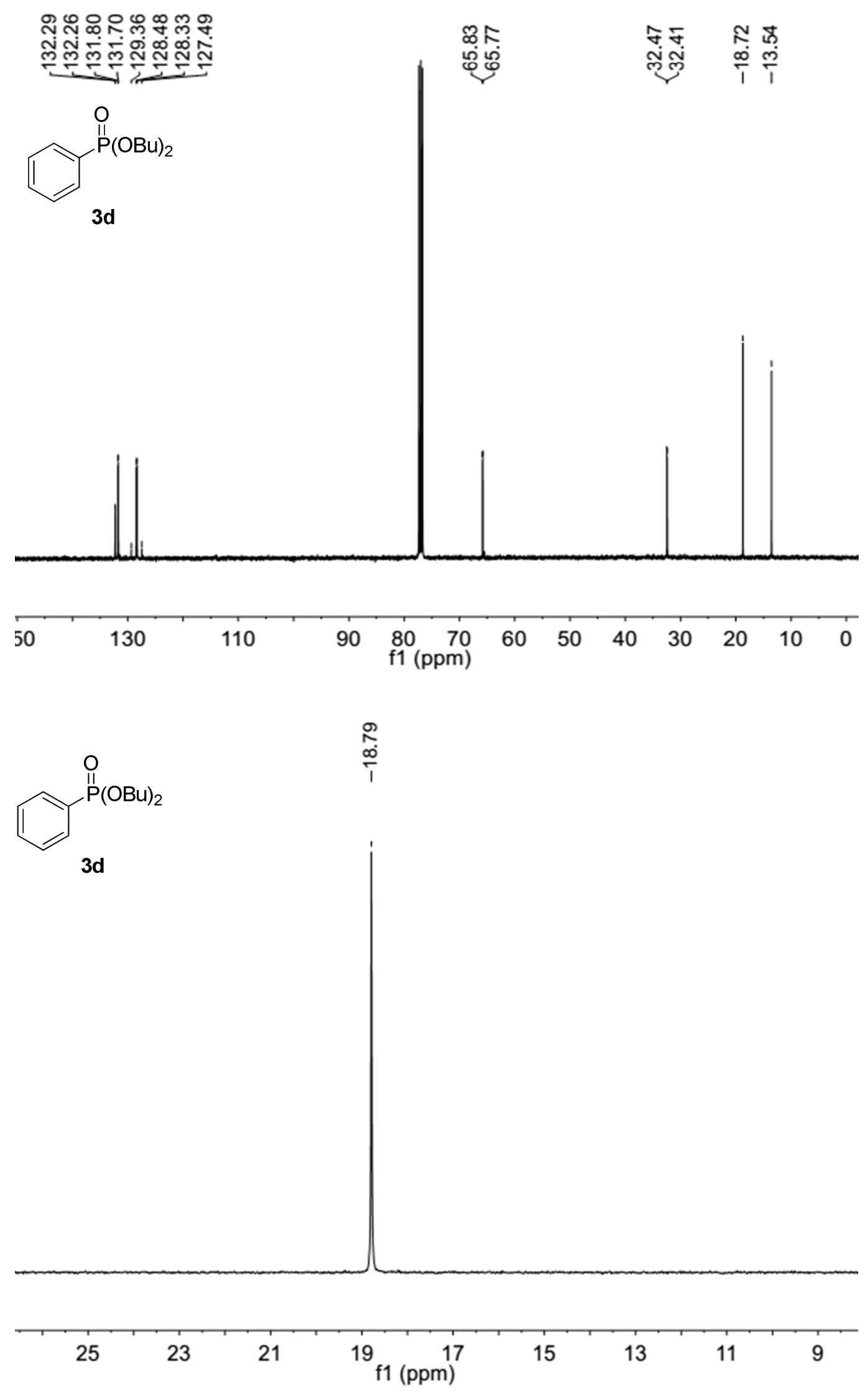


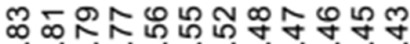

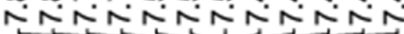

$3 e$

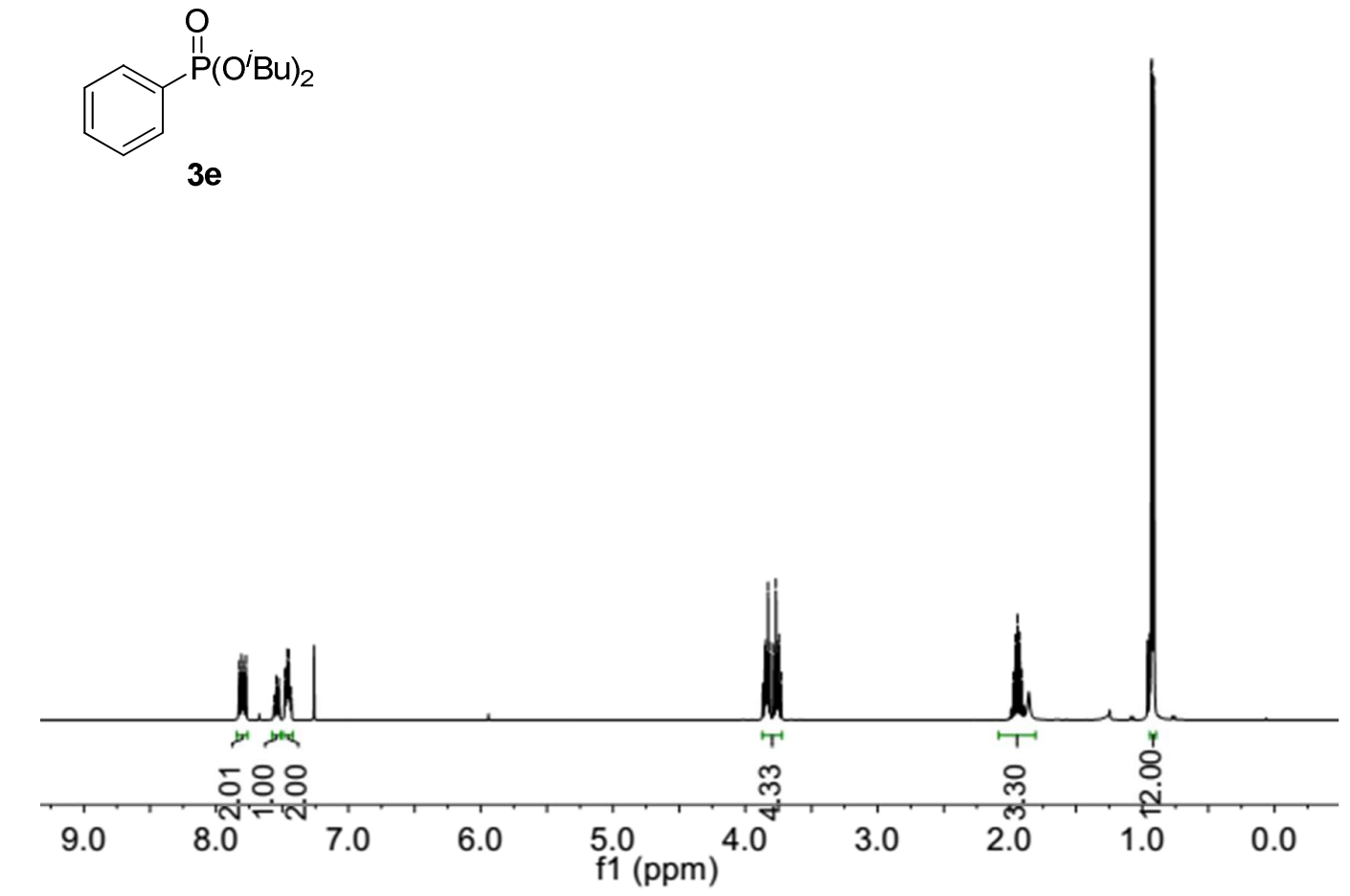

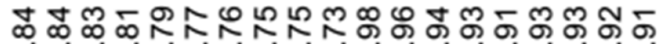

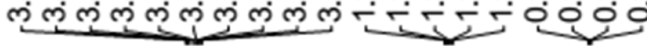
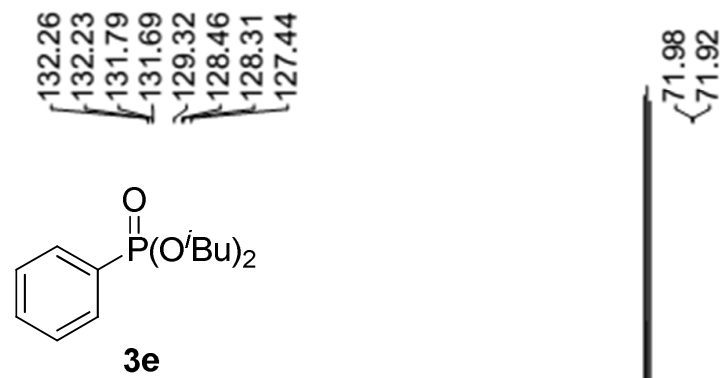

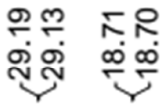
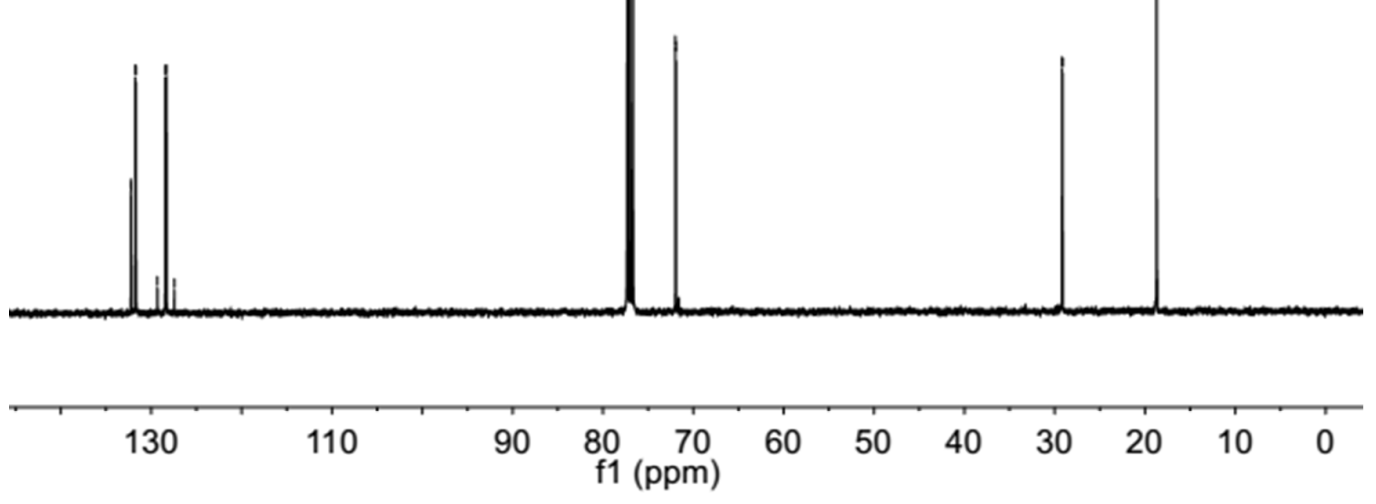


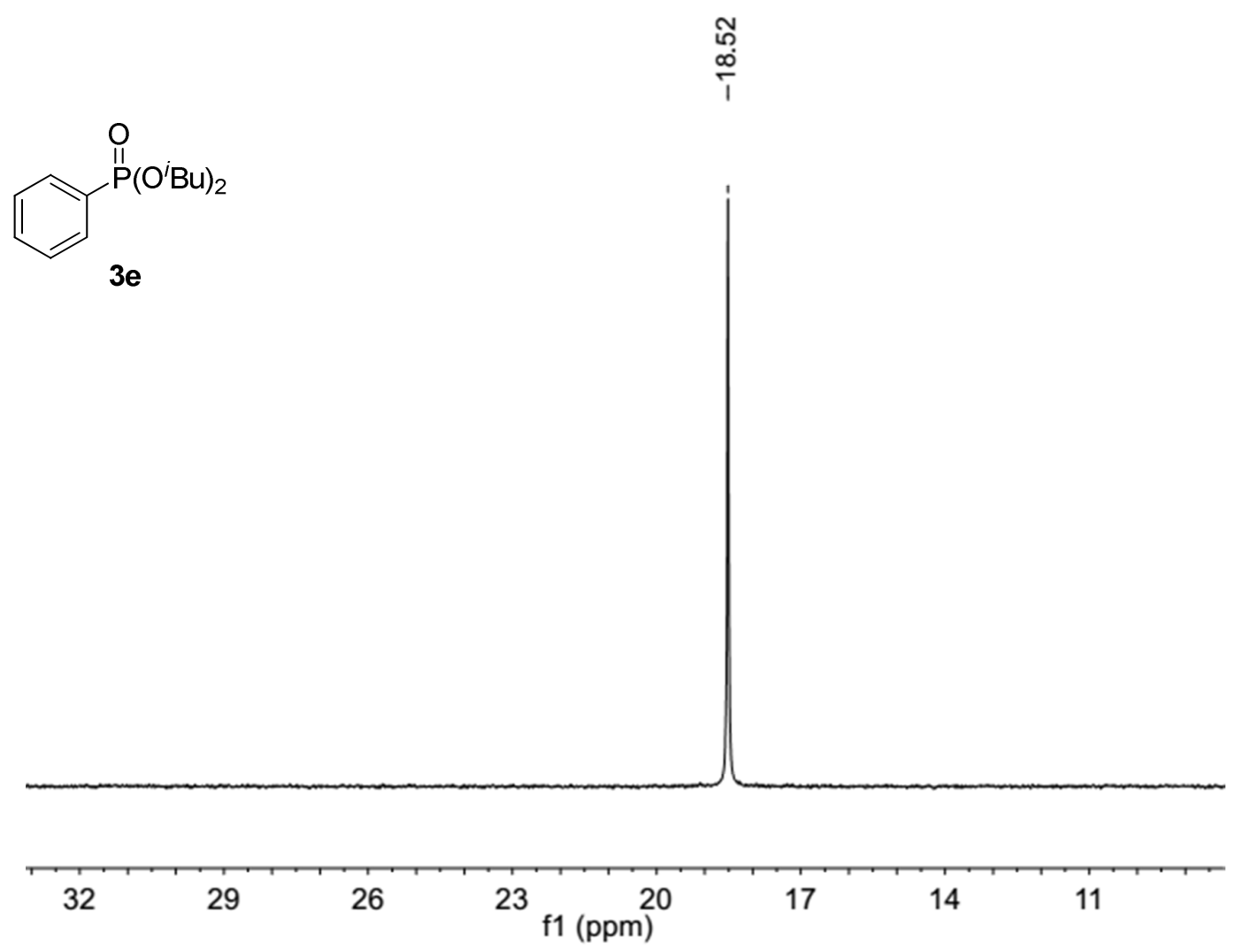

œ

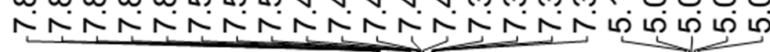<smiles>O=[Pb](O)c1ccccc1</smiles>

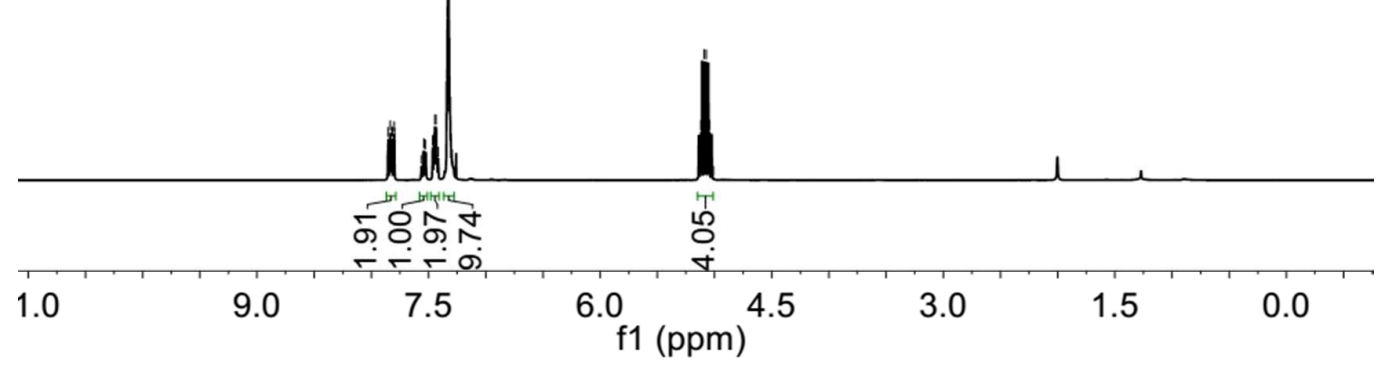




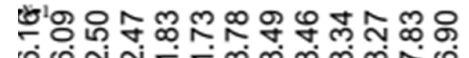

மூ

부요

ஸिं

$\overbrace{3 \mathbf{f}}^{\mathrm{O}} \mathrm{P}(\mathrm{OBn})_{2}$

$\begin{array}{llllllllllll}150 & 130 & 110 & 90 & \begin{array}{l}80 \\ \mathrm{f} 1(\mathrm{ppm})\end{array} & 60 & 50 & 40 & 30 & 20 & 10 & 0\end{array}$<smiles>CCCCOP(=O)(c1ccccc1)c1ccccc1</smiles>

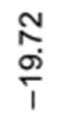

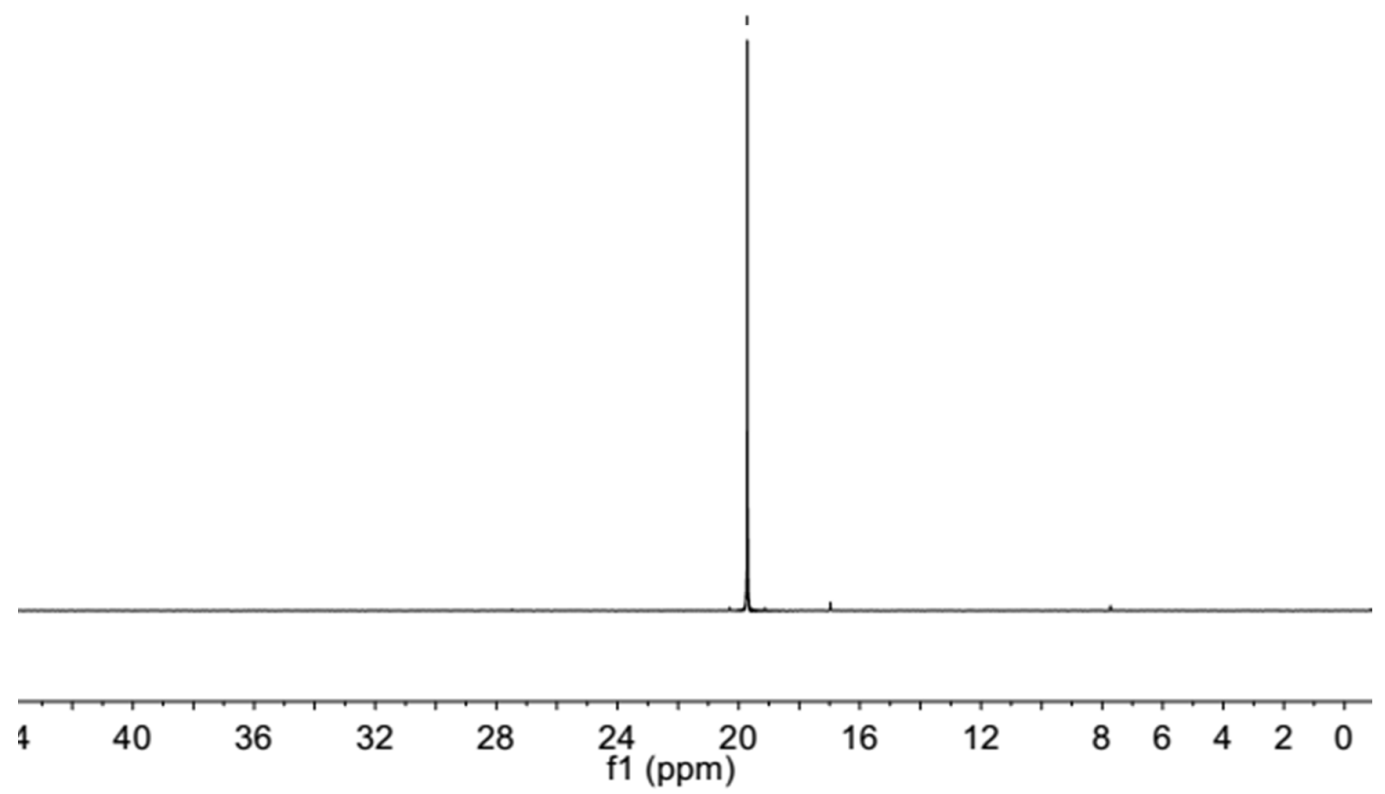



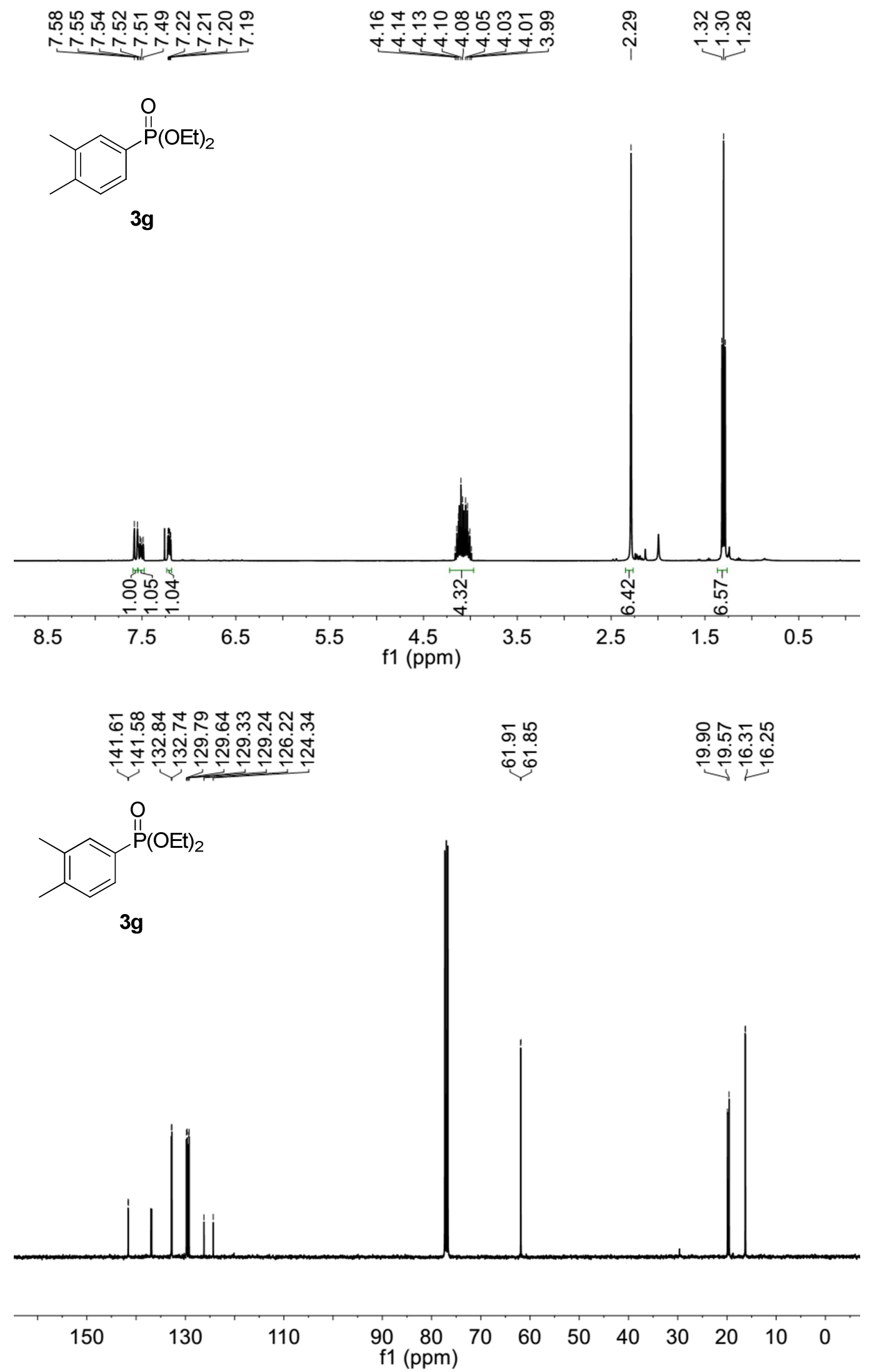

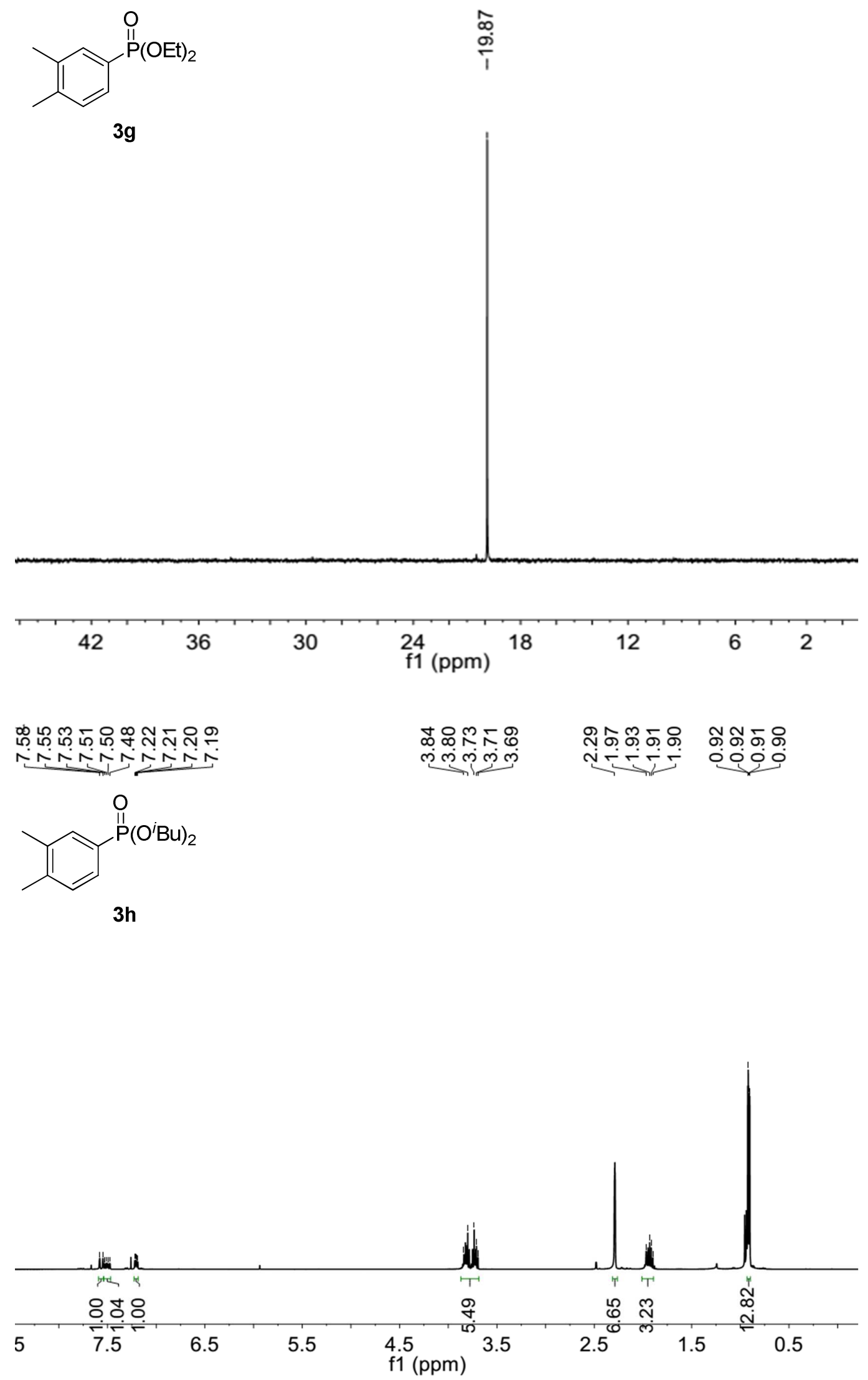


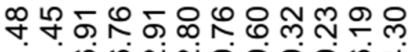

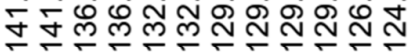

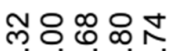

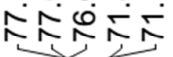

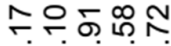

ลุ่

$\overbrace{}^{\mathrm{P}}\left(\mathrm{O}^{\prime} \mathrm{Bu}\right)_{2}$

3h
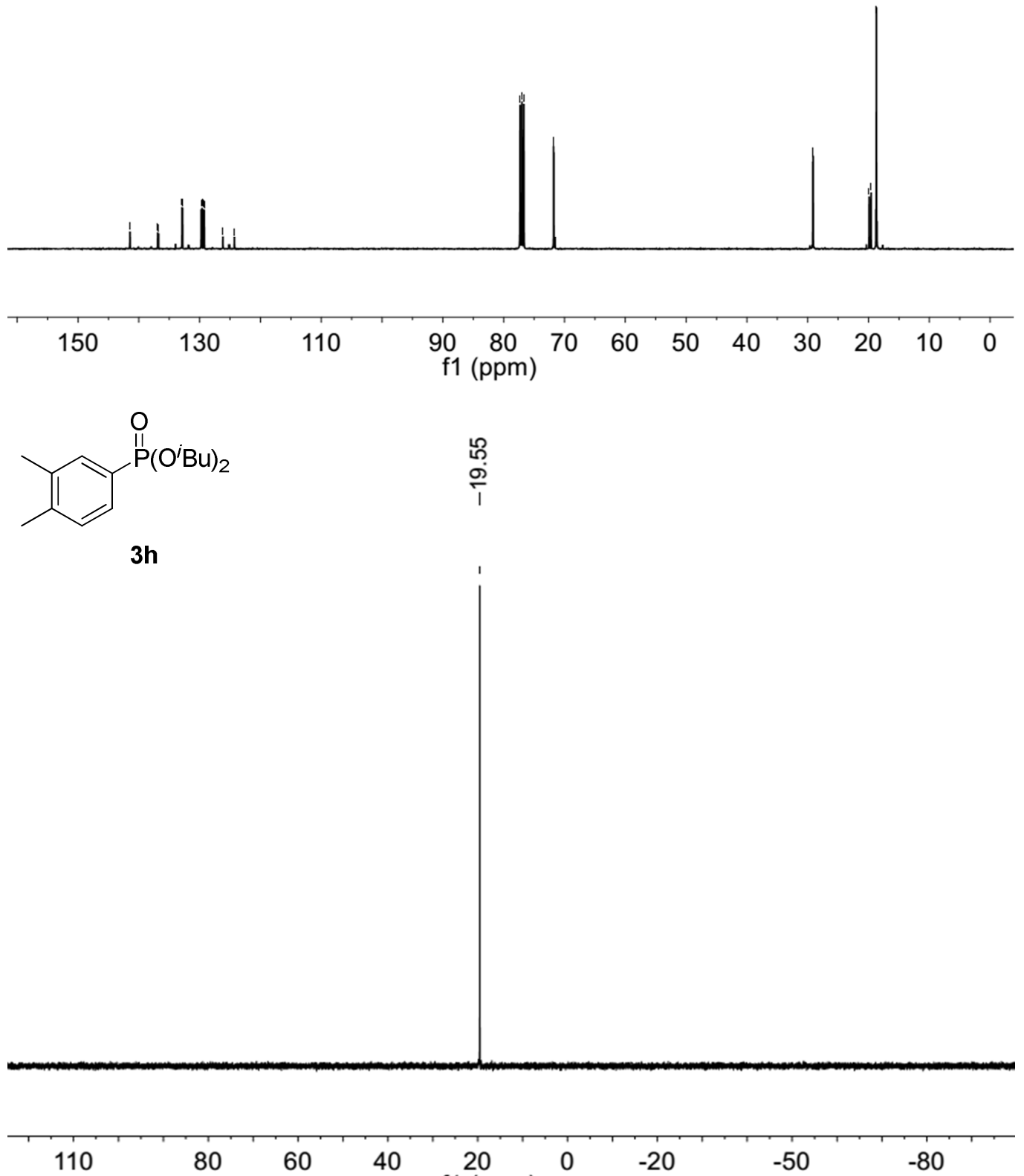

60

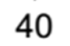

20

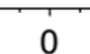

$-20$

$-50$

$-80$ 
กำกำ

NNNNNN

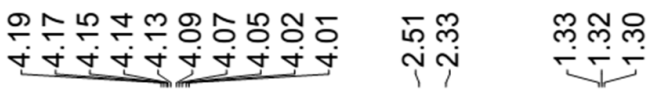<smiles>CCOP(=O)(OCC)c1cc(C)ccc1C</smiles>

$3 \mathbf{i}$

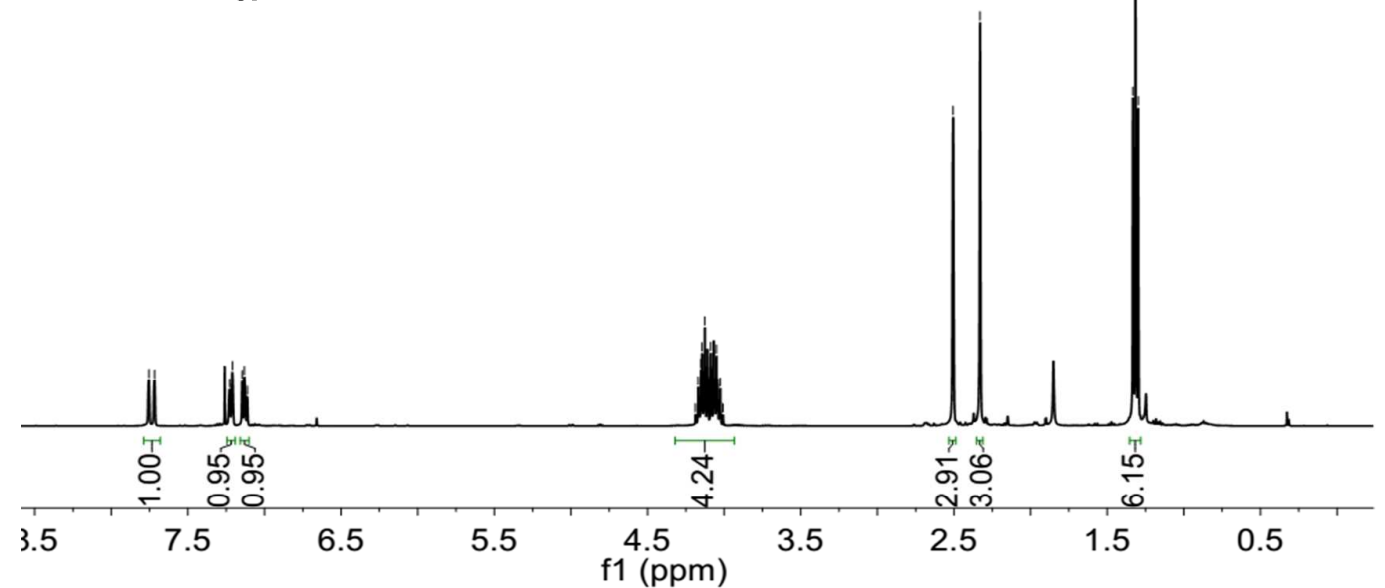

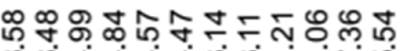

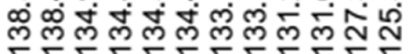
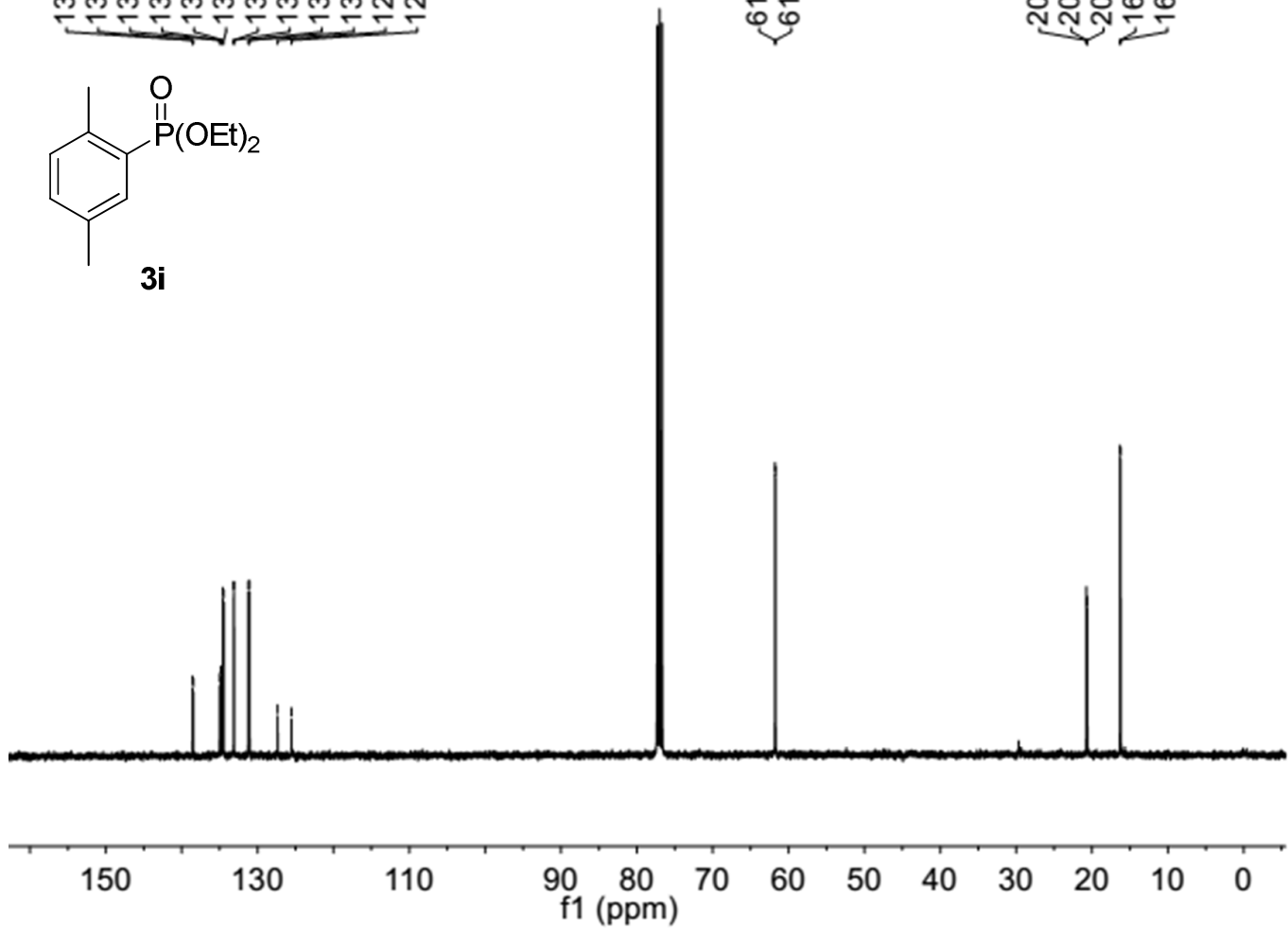
ণั่
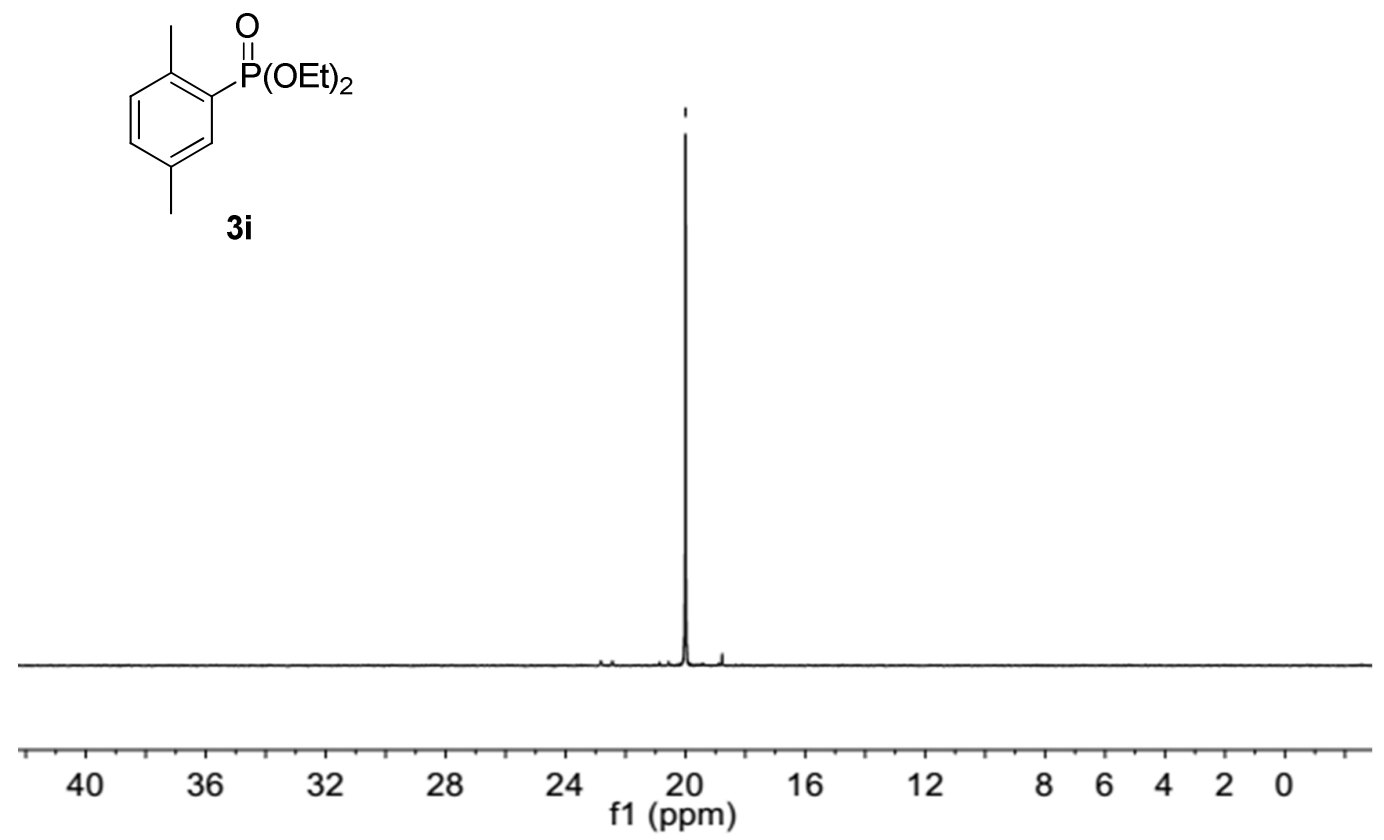

กรกำ

NNNNNN

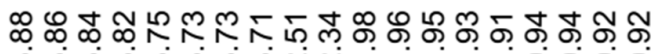

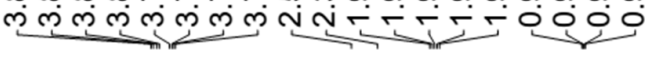

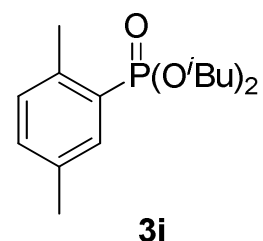

3j

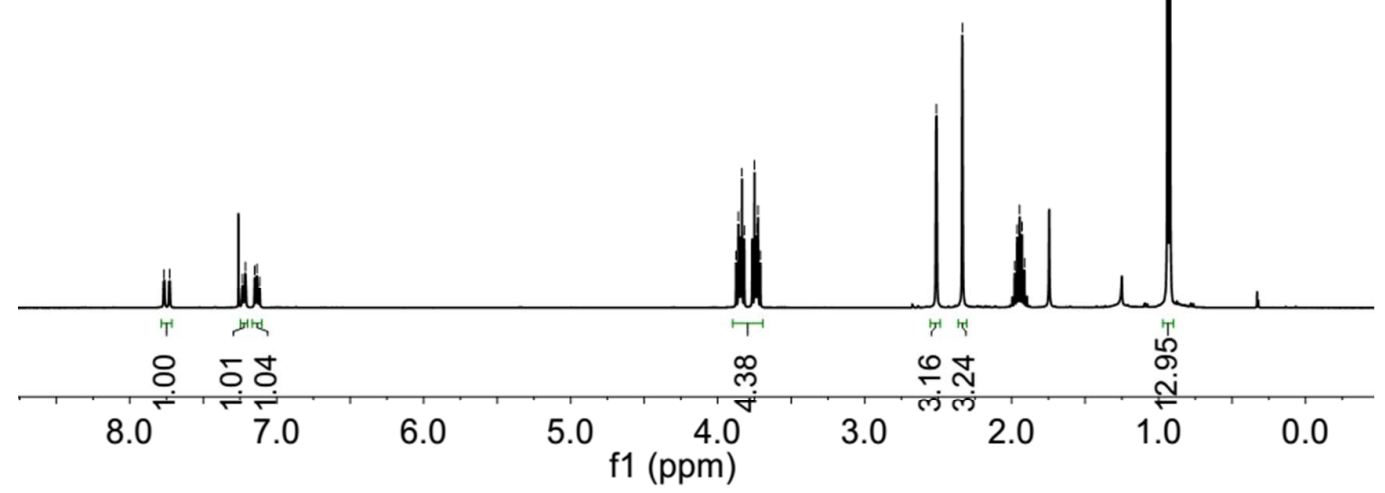



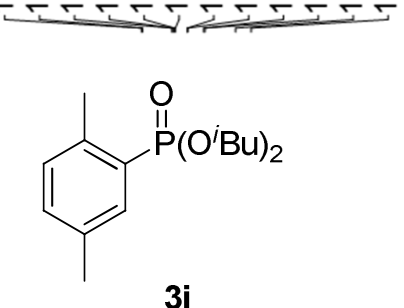

3j
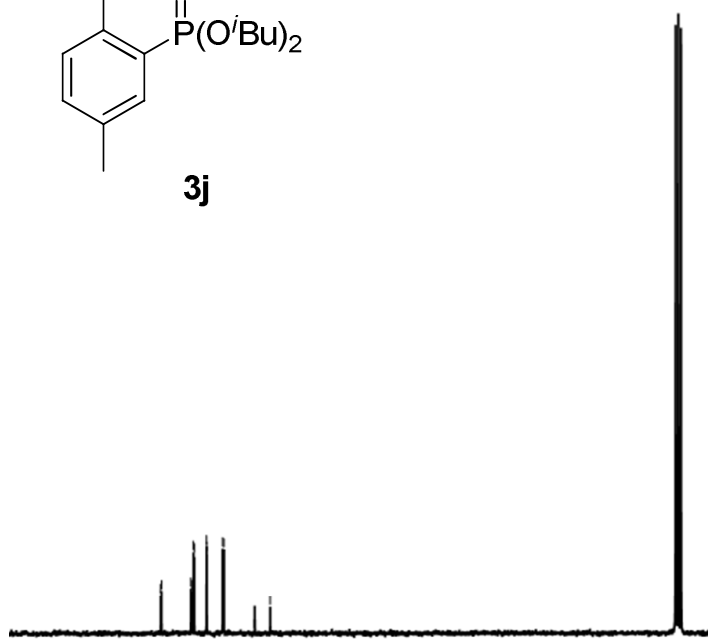

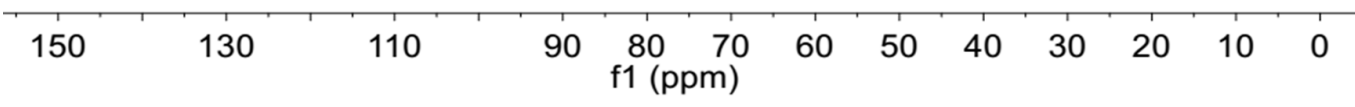

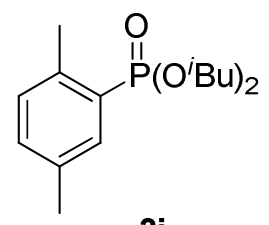

ลั

ণิ

3j

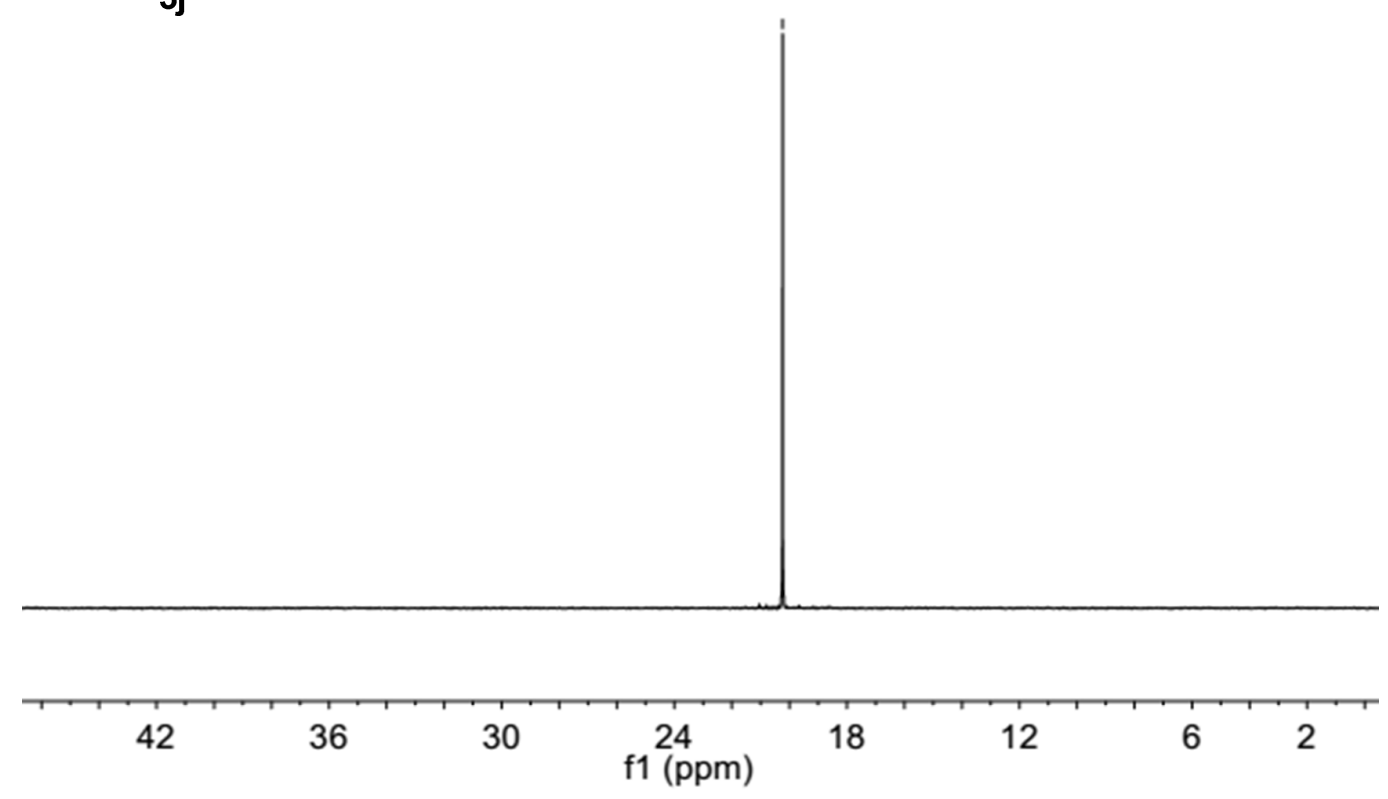



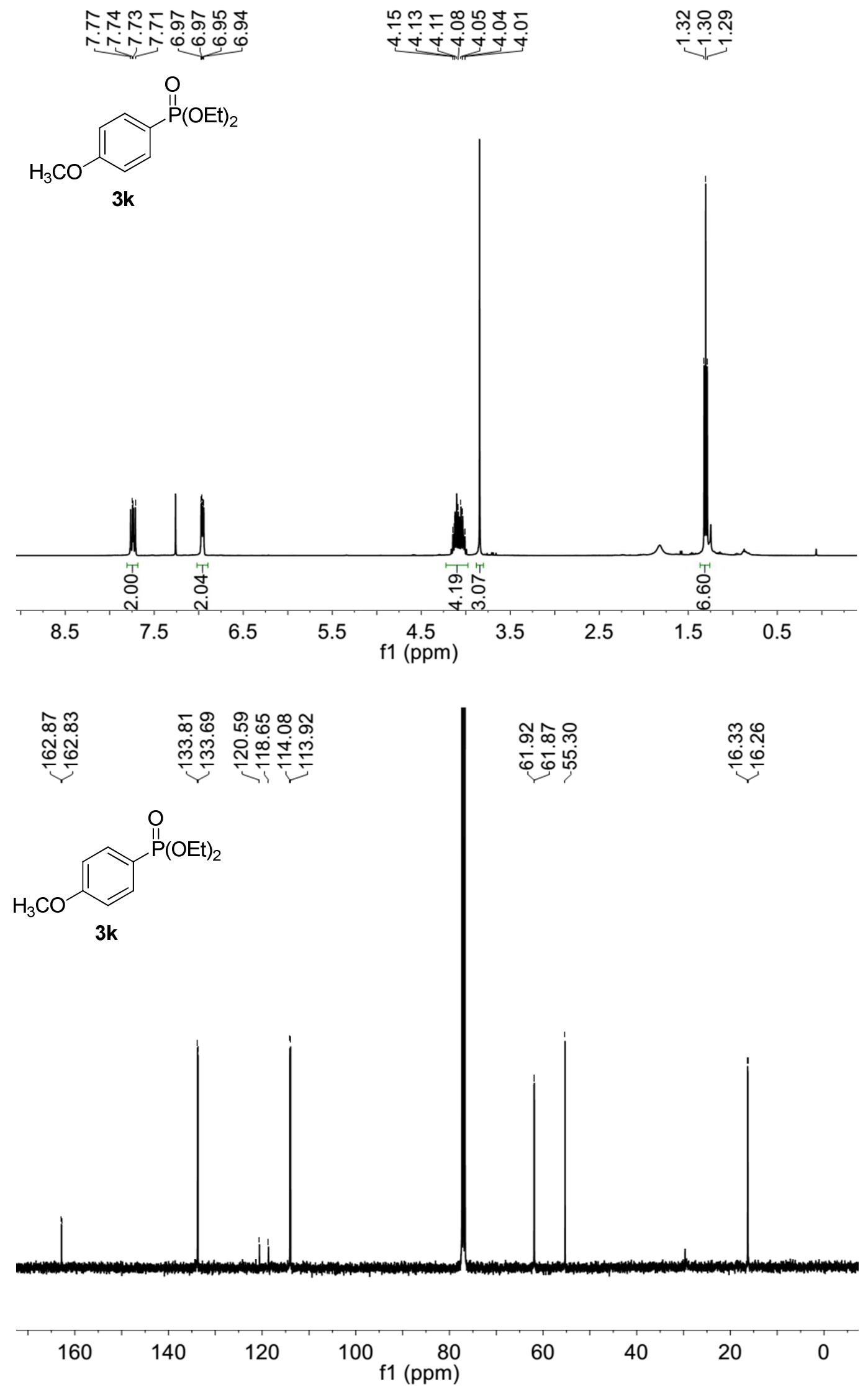


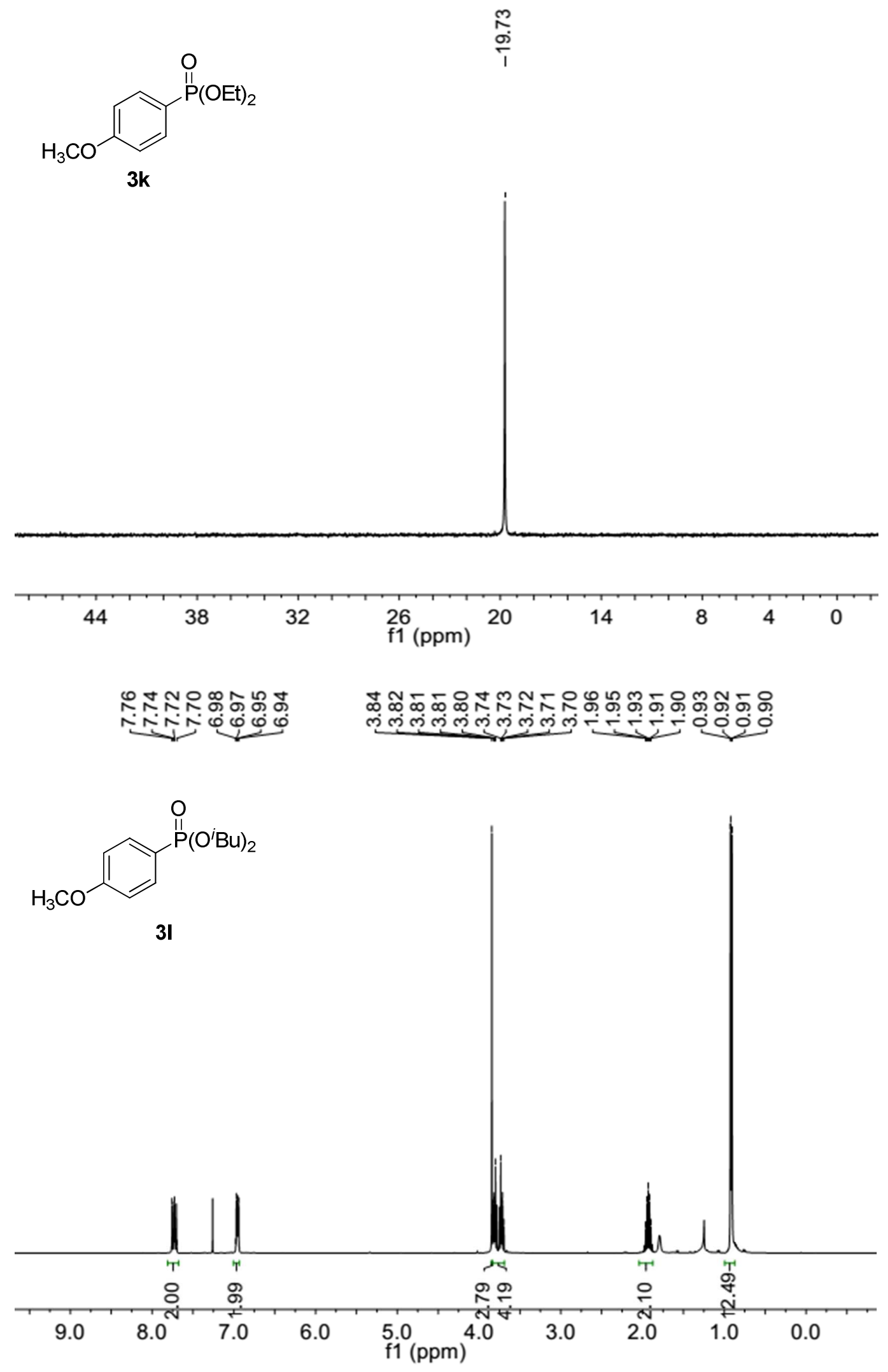



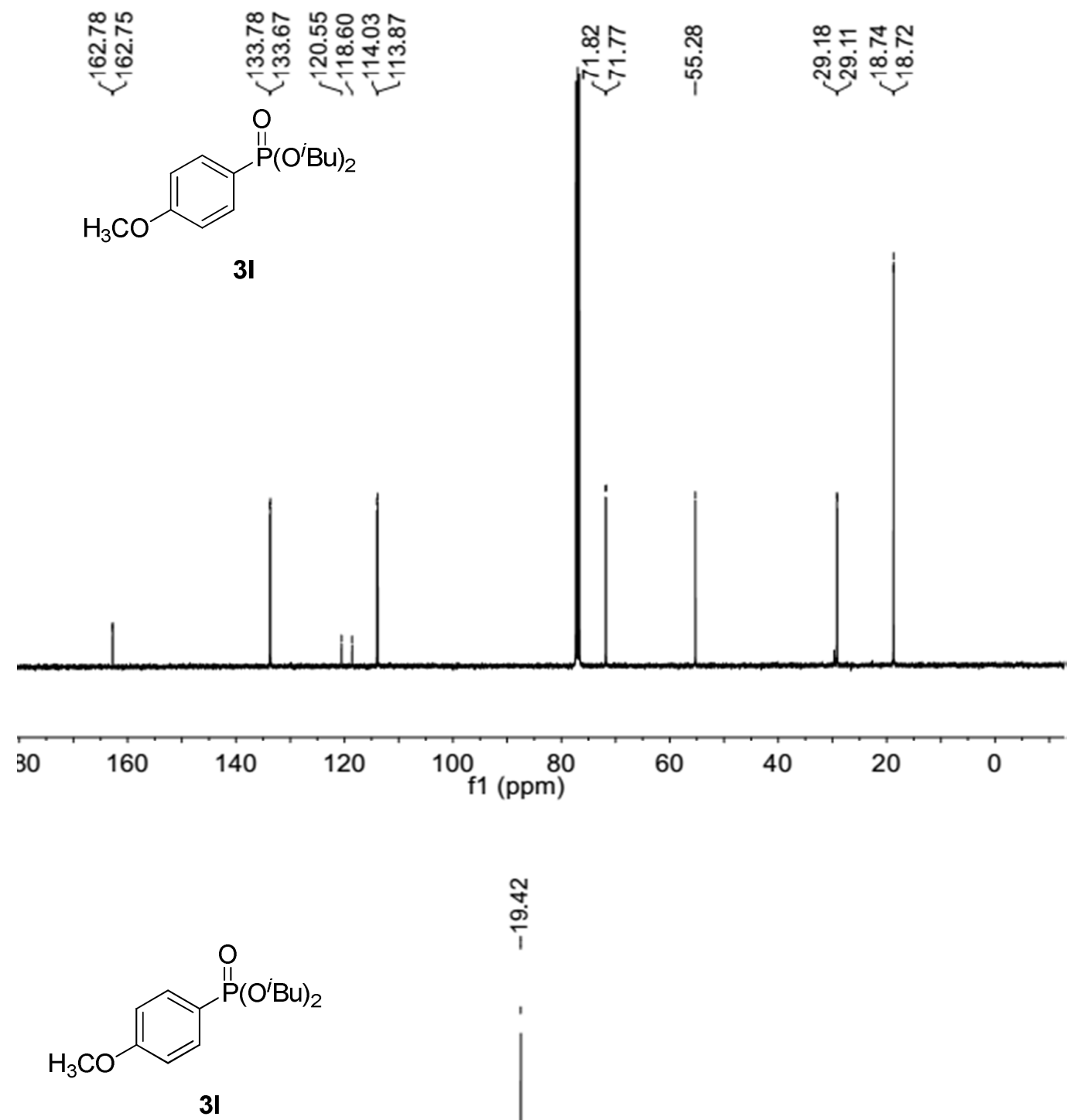

$\frac{\text { จ }}{\frac{1}{1}}$

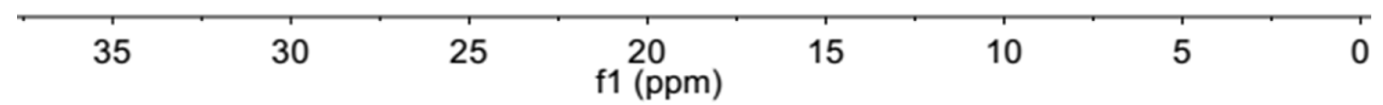




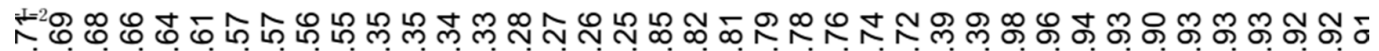

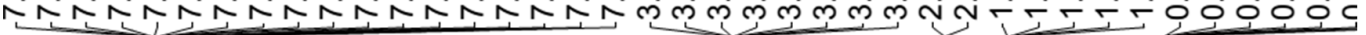<smiles>Cc1ccc(P(=O)(OC(C)(C)C)c2ccccc2)cc1</smiles>

$3 \mathrm{~m}$

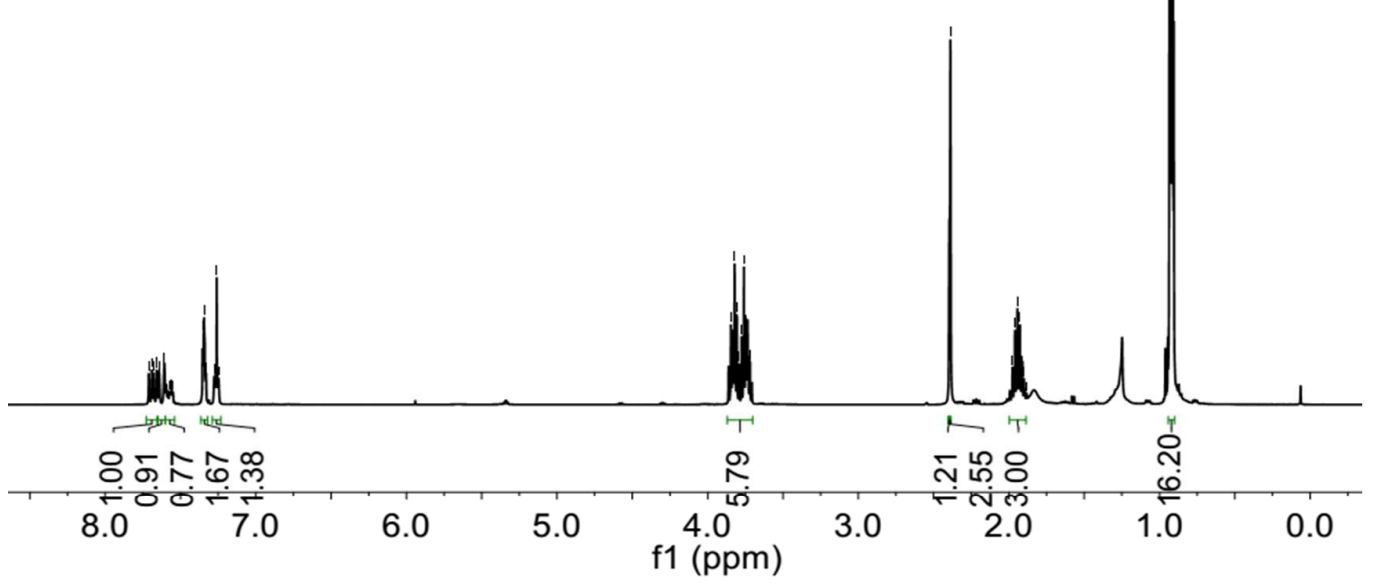

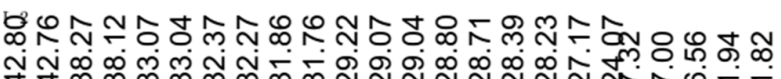

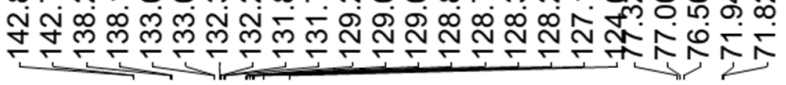

กฺุ

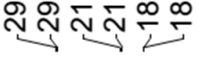<smiles>Cc1ccc(P(=O)(OC(C)(C)C)c2ccccc2)cc1</smiles>

$3 m$
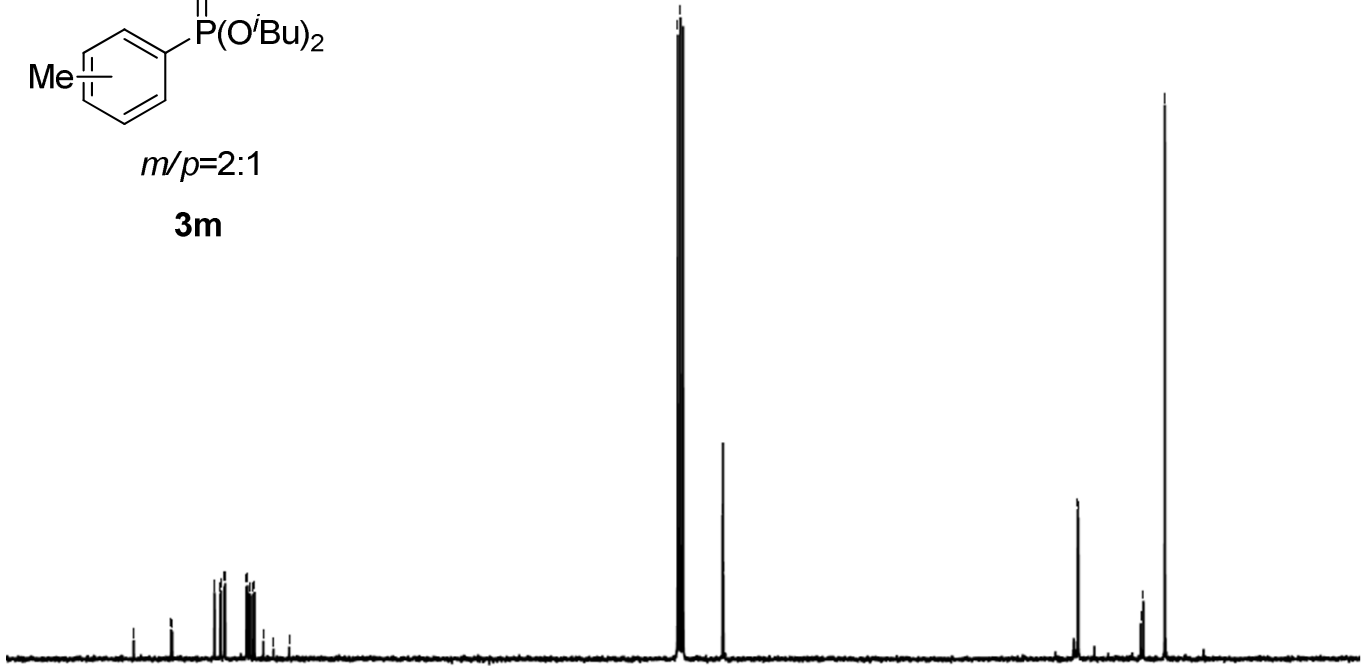

$150 \quad 130 \quad 110 \quad 90 \begin{gathered}8070 \\ \mathrm{f} 1(\mathrm{ppm})\end{gathered}$


<smiles>CCCCOP(=O)(OCCCC)c1ccccc1</smiles>

$3 m$

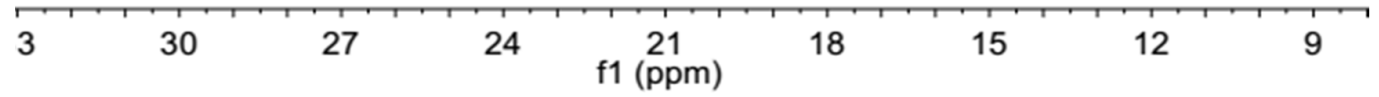

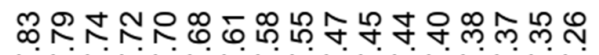

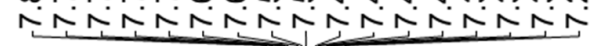<smiles>CCCCOP(=O)(OCCC)c1ccc(Br)cc1</smiles>

$3 n$

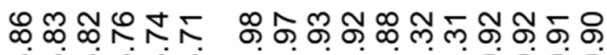

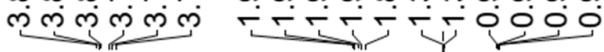

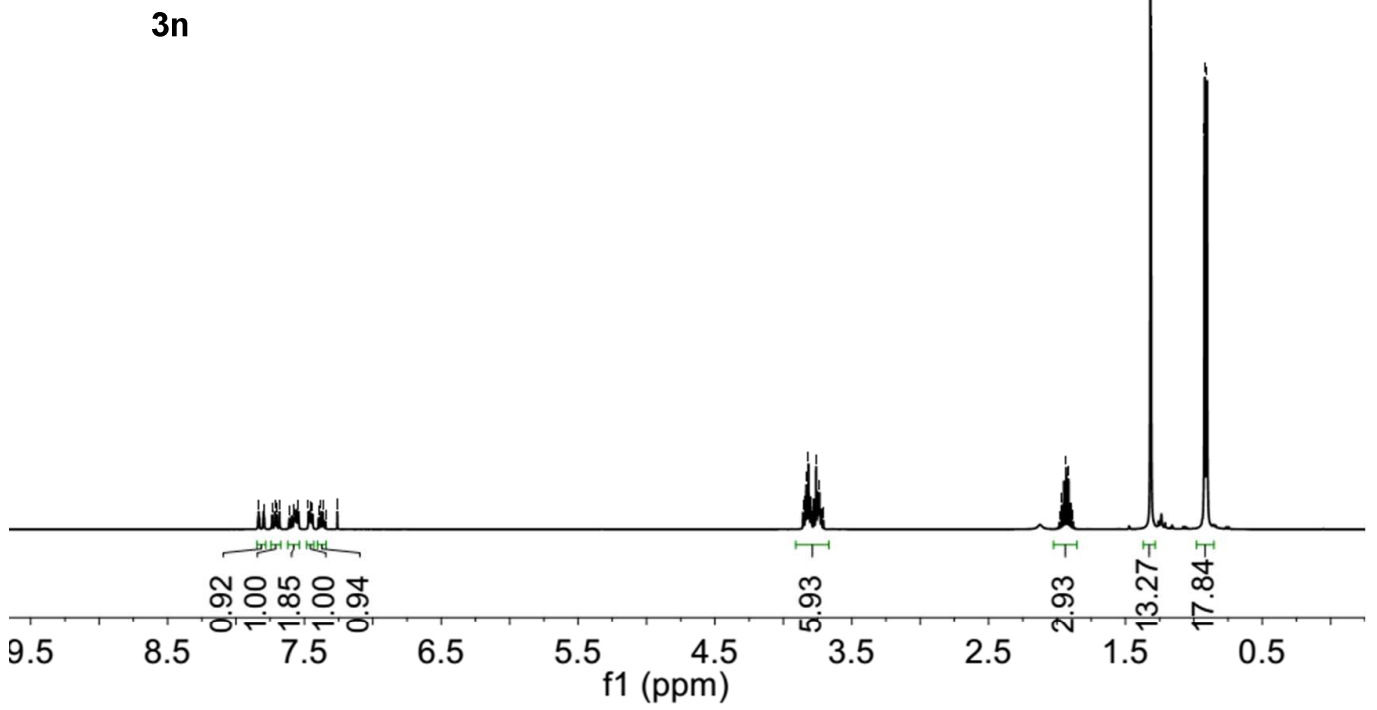




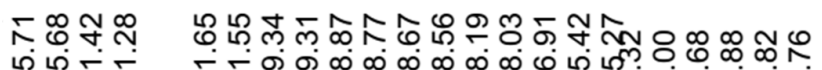

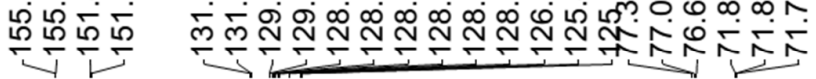

으융융유융

लं

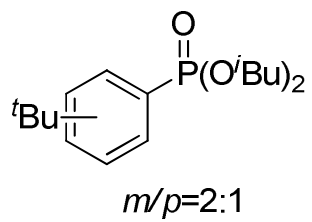

$3 n$

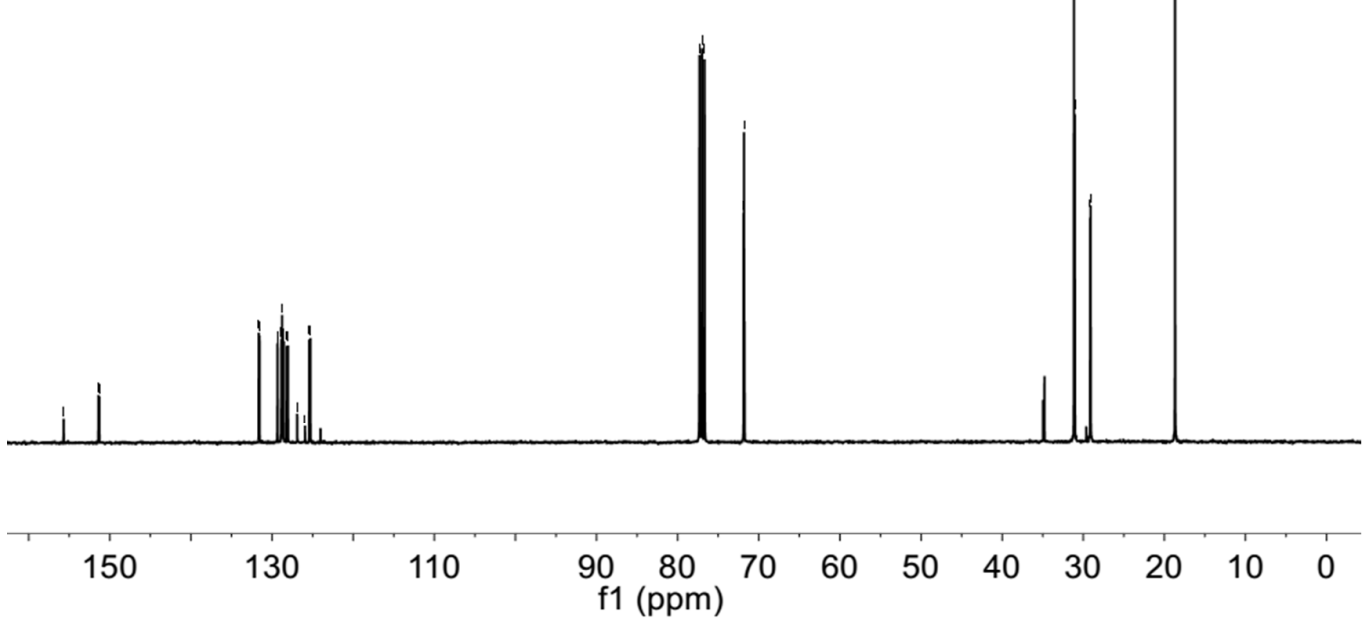<smiles>CCCCO[PH](=O)c1ccc(Br)cc1</smiles>

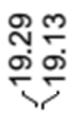

$3 n$

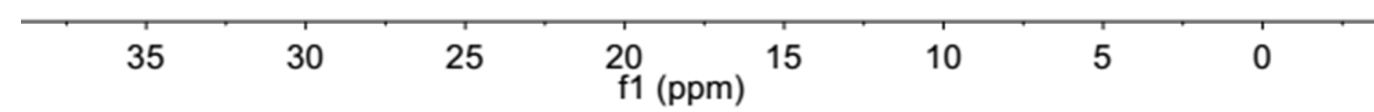




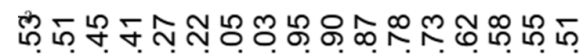
$\infty \infty \infty \infty \infty \infty \infty \infty N N N N N N$<smiles>CCCCOP(=O)(OCC)c1ccc2ccccc2c1</smiles>

30

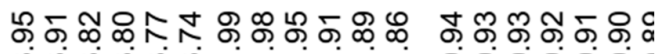

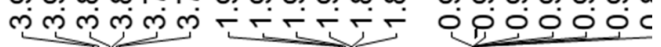

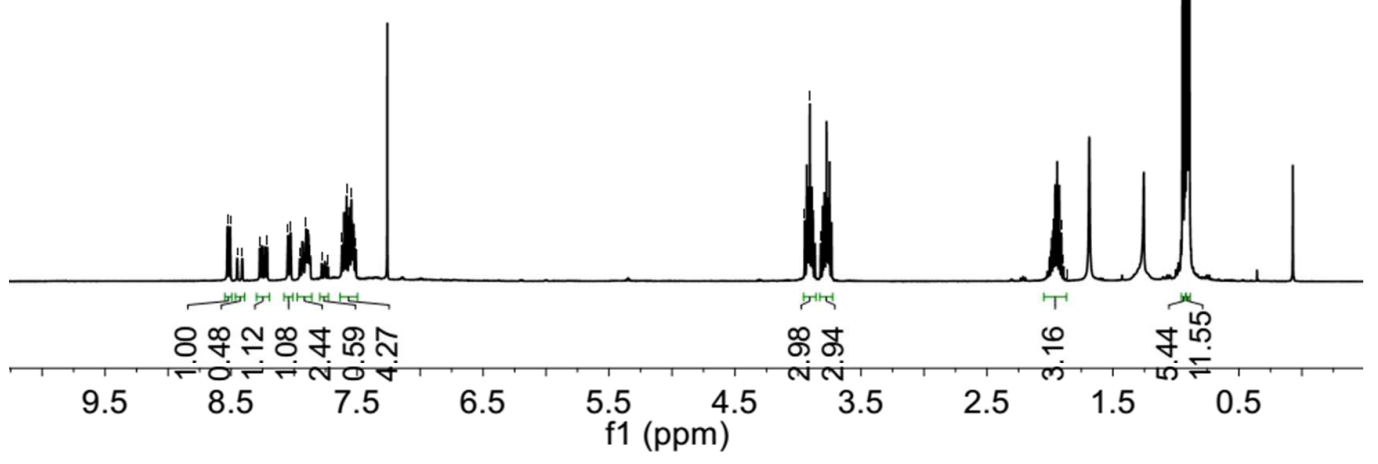

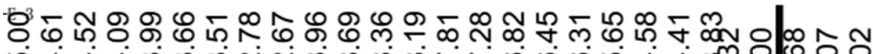

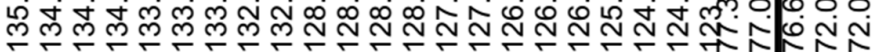<smiles>CCCCOP(=O)(OCCCC)c1ccc2ccccc2c1</smiles>
$\alpha / \beta=2: 1$

3o

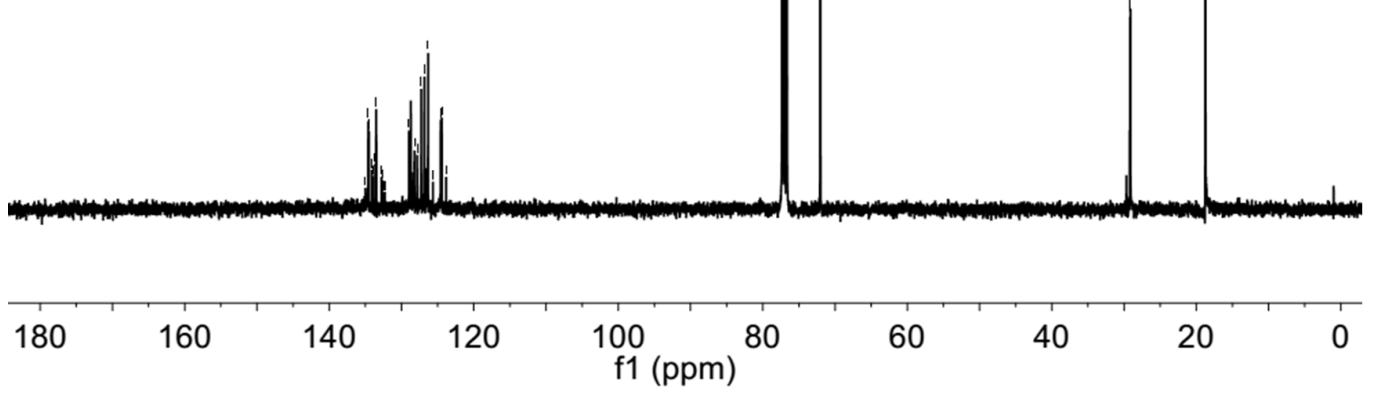




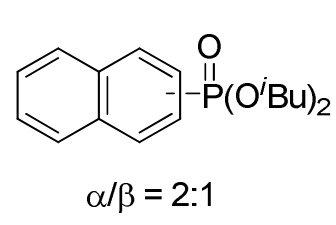

3o

\begin{tabular}{|c|c|c|c|c|c|c|c|}
\hline 44 & 38 & 32 & & $\begin{array}{r}20 \\
\text { f1 (ppm) }\end{array}$ & 14 & 8 & 4 \\
\hline
\end{tabular}

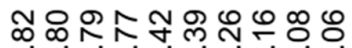

NANTNANA

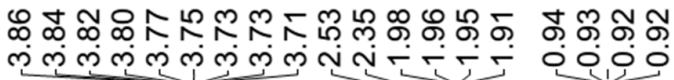<smiles>CCCCOP(=O)(OCCCC)c1cc(C)cc([18OH])c1</smiles>

$3 p$

$3 p$

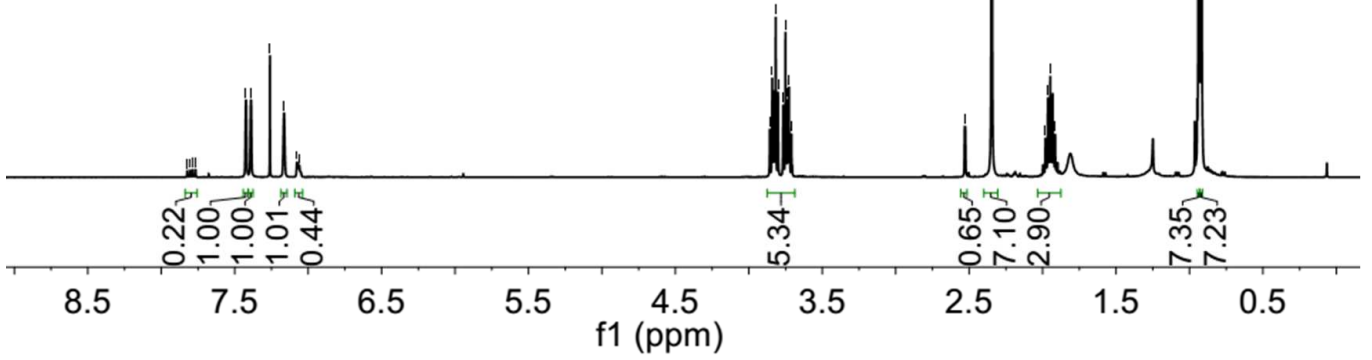



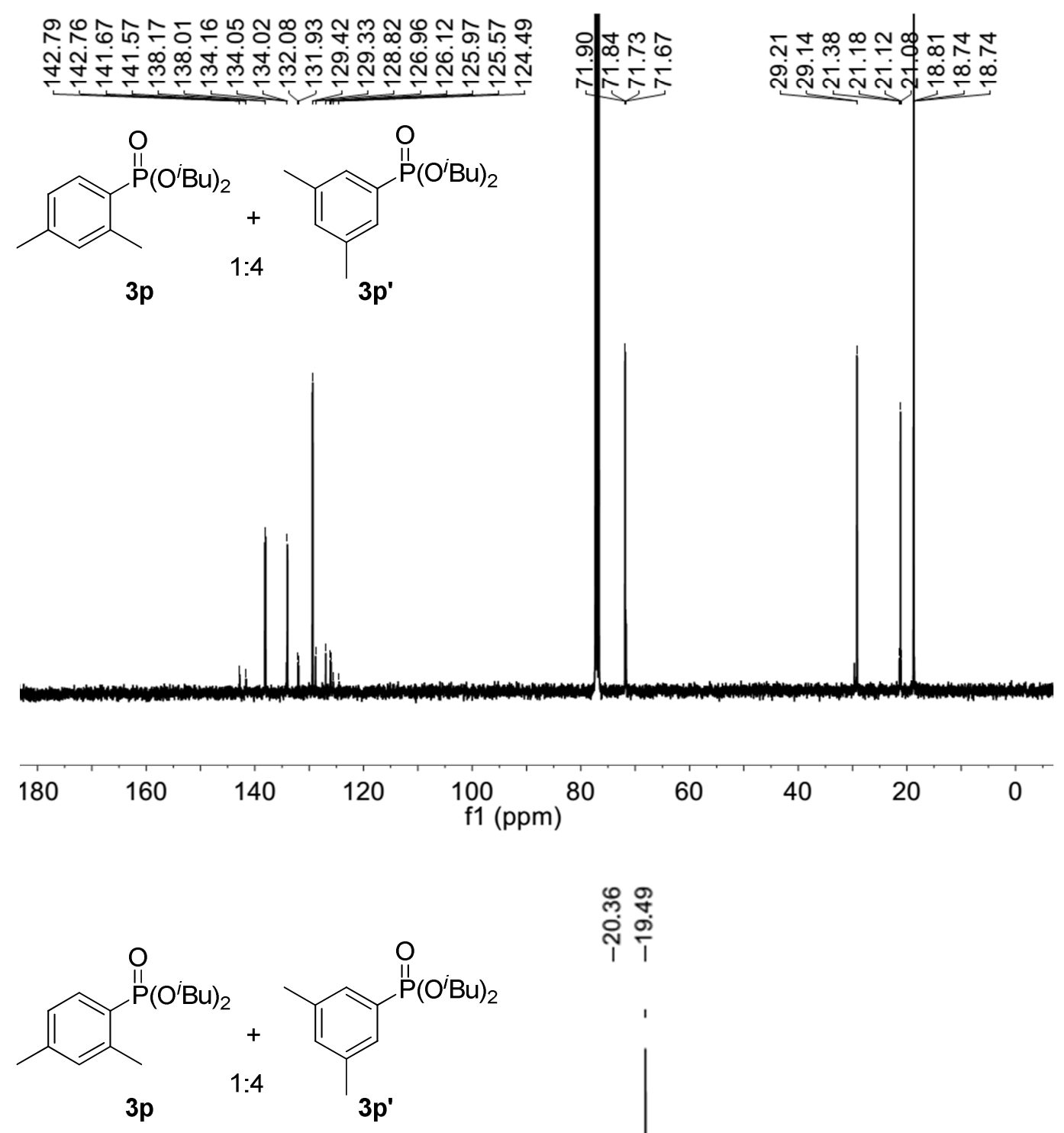

ஸ্ণ

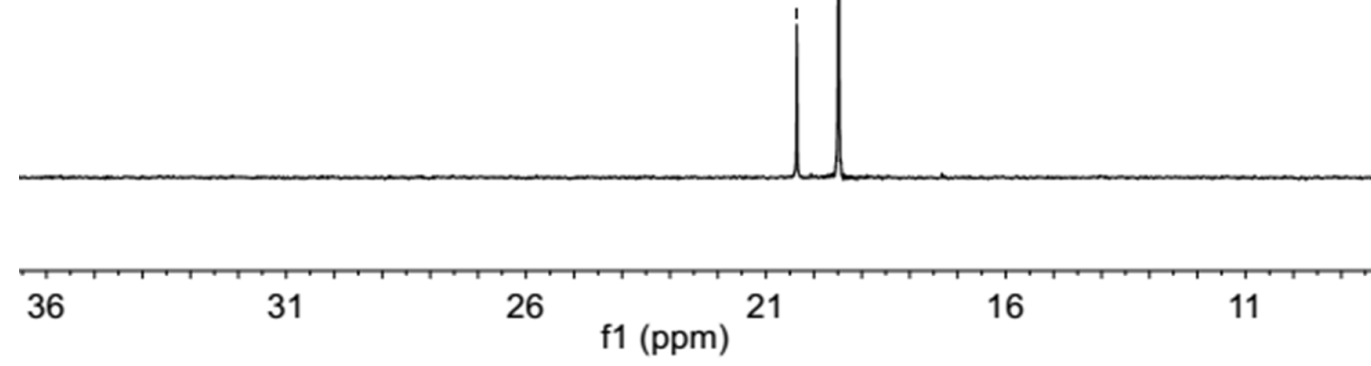




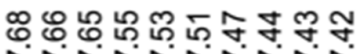

NNNNNNNNN<smiles>O=[PH+](P)c1ccccc1</smiles>

$5 a$

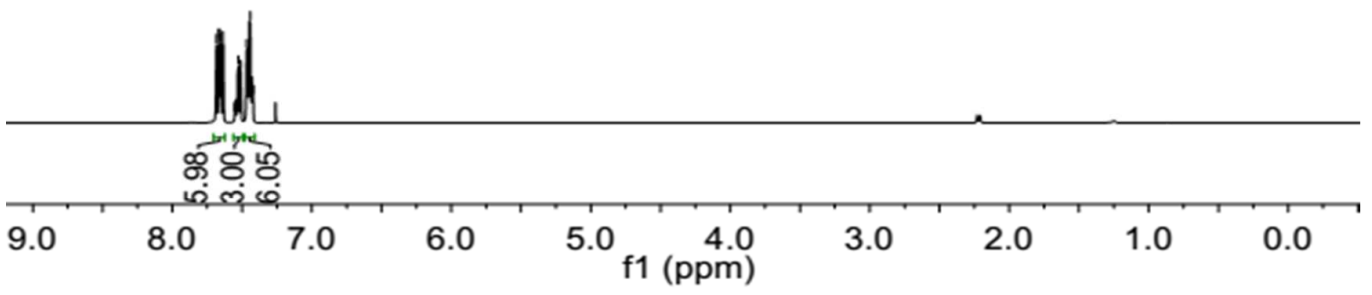

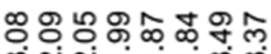

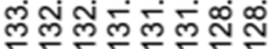
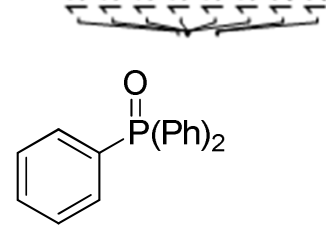

$5 a$

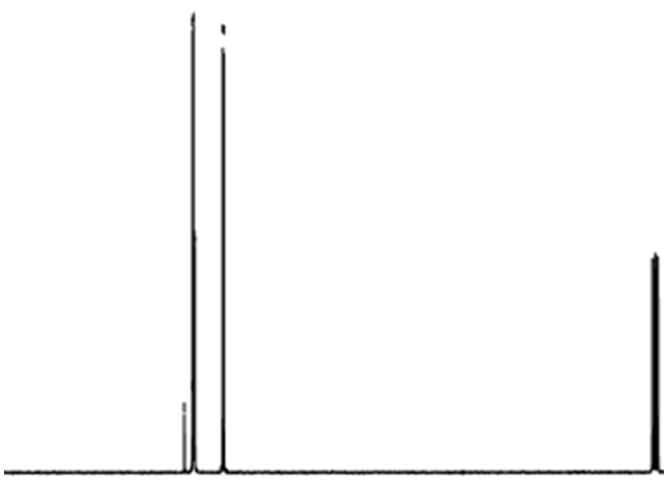

$150 \quad 130 \quad 90 \begin{array}{r}80 \\ \mathrm{f} 1(\mathrm{ppm})\end{array} \quad \begin{array}{lllllllll}70 & 60 & 50 & 40 & 30 & 20 & 10 & 0\end{array}$




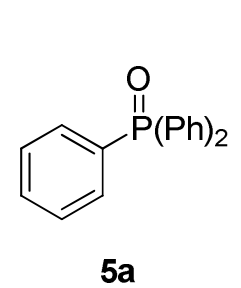

$\frac{\circ}{\text { 우 }}$

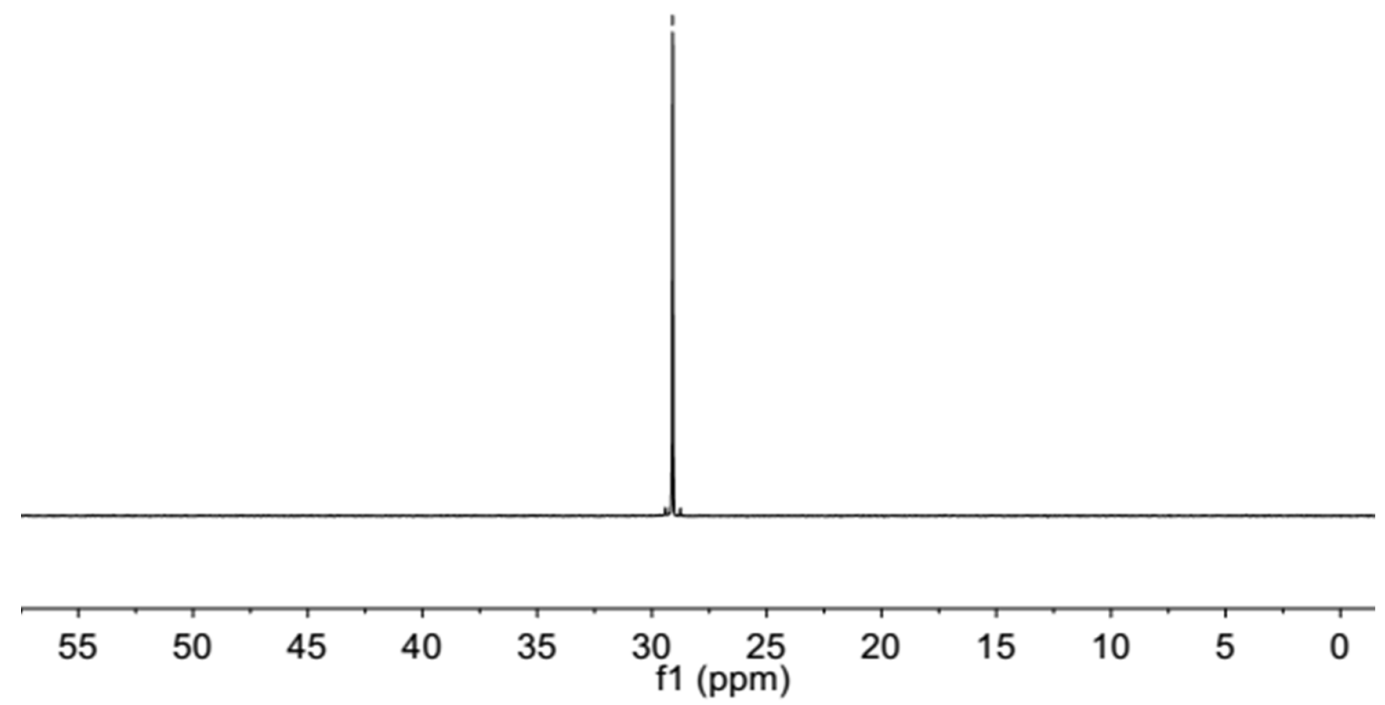

"11-1

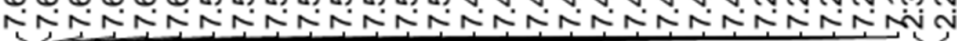<smiles>Cc1ccc(P(=O)(O)c2ccccc2)cc1C</smiles>

$5 b$

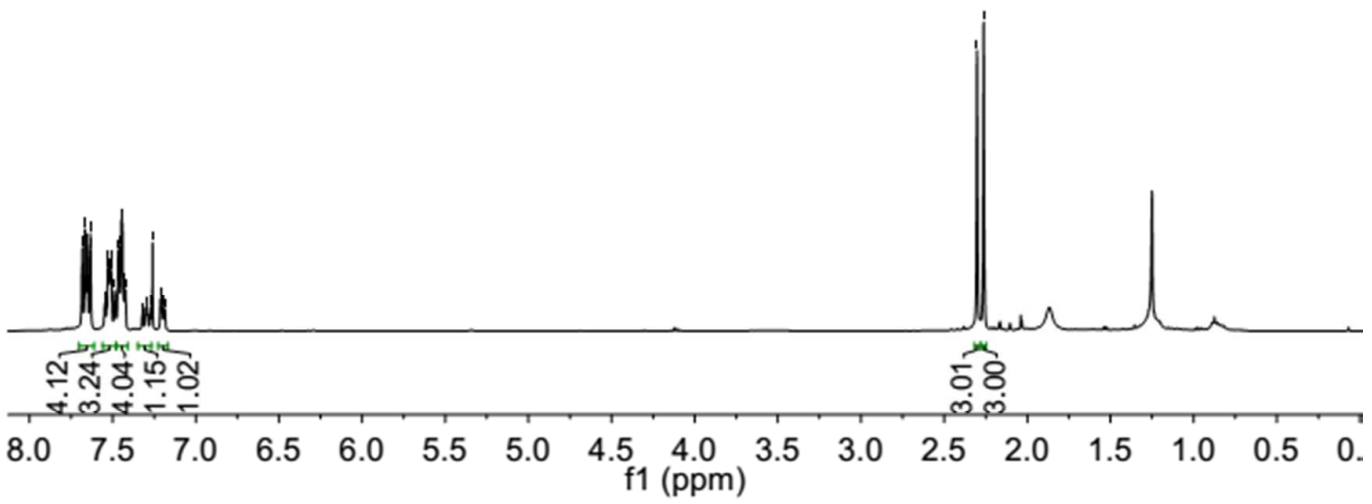



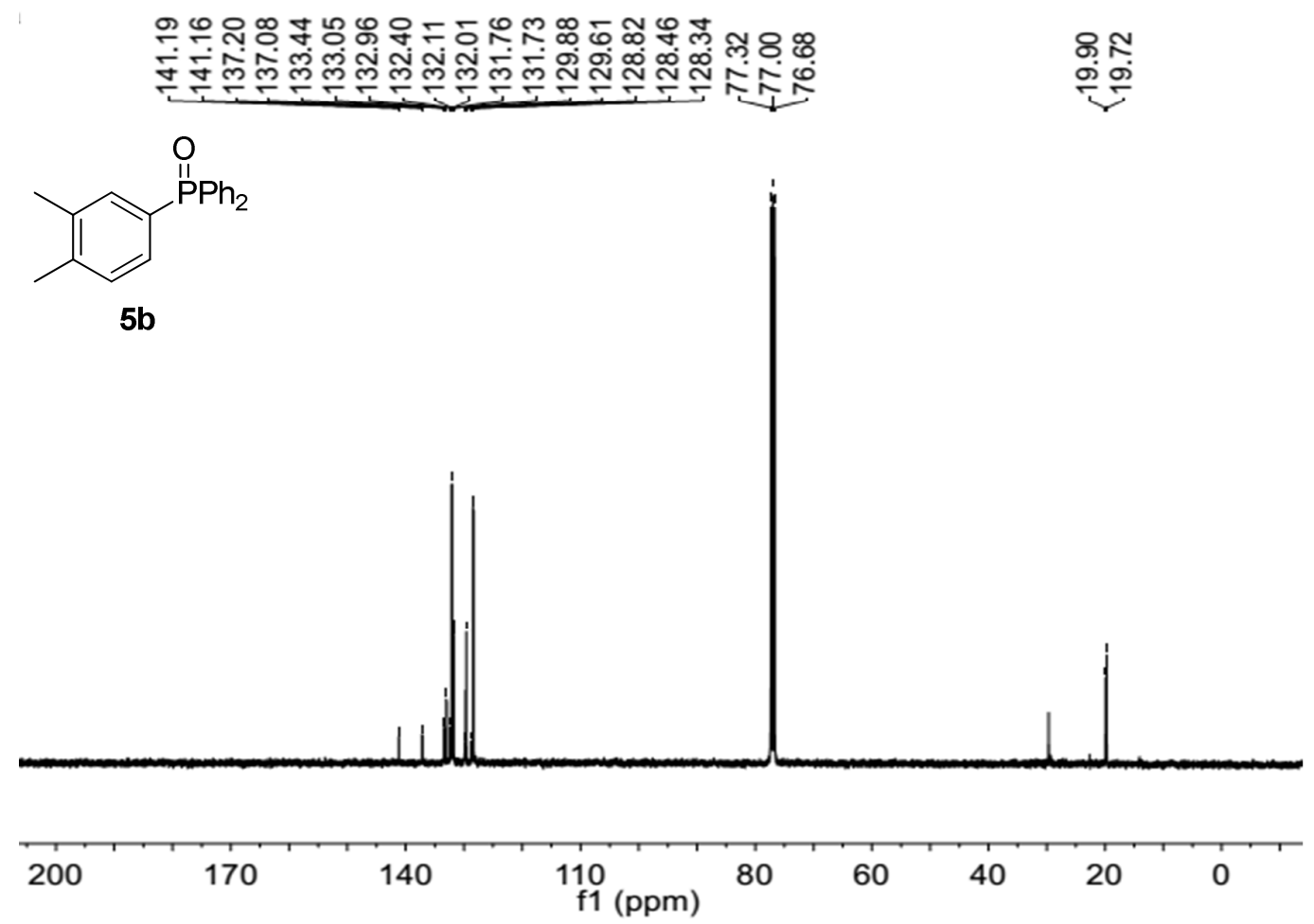

ষ্ণ
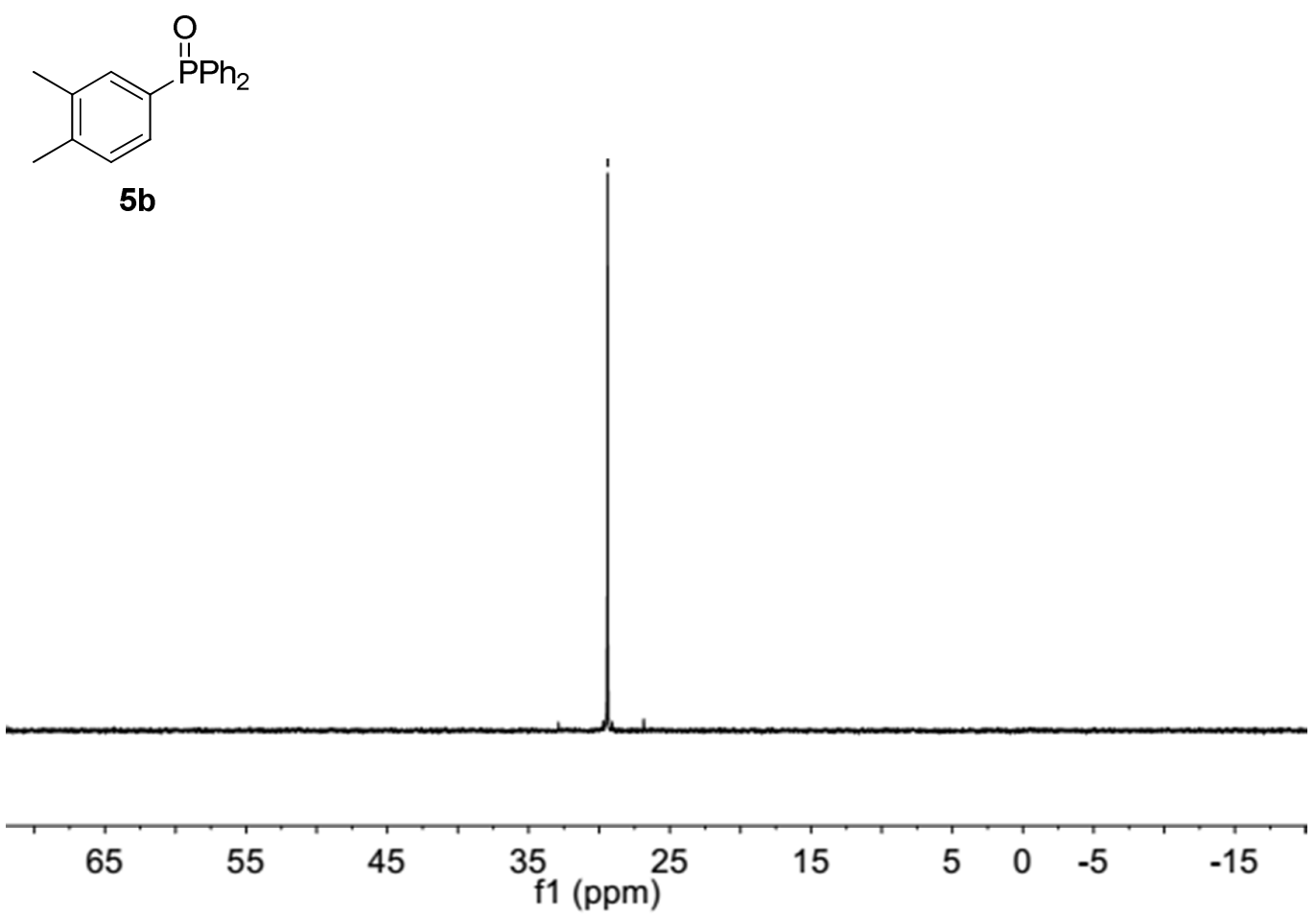


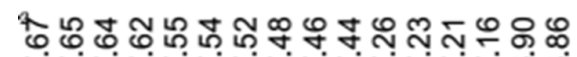

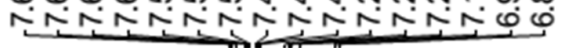

유규

กิ<smiles>Cc1ccc(C)c(P(=O)(O)c2ccccc2)c1</smiles>

5c

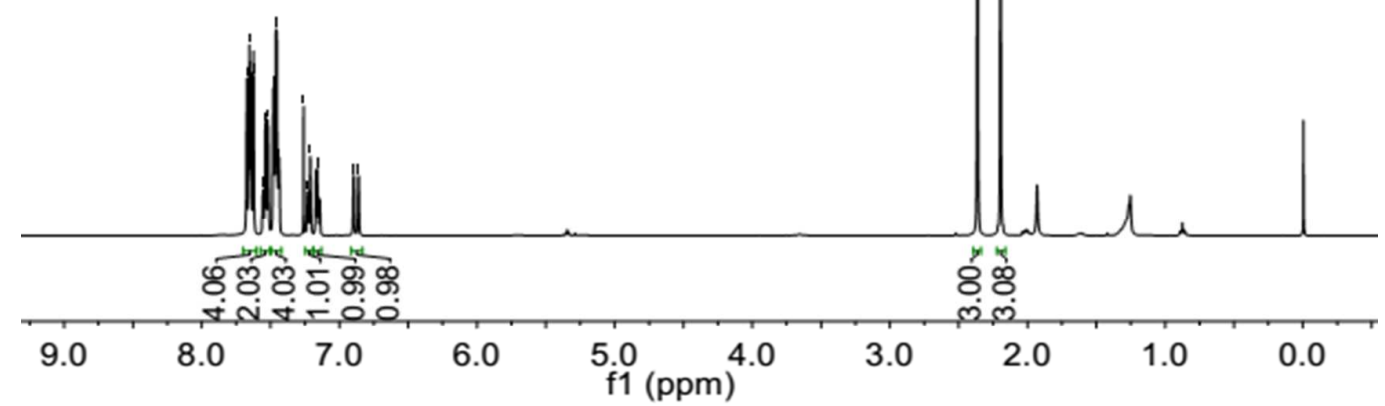

"

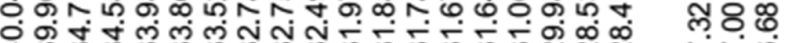
可<smiles>Cc1ccc(C)c(P(=O)(P)c2ccccc2)c1</smiles>

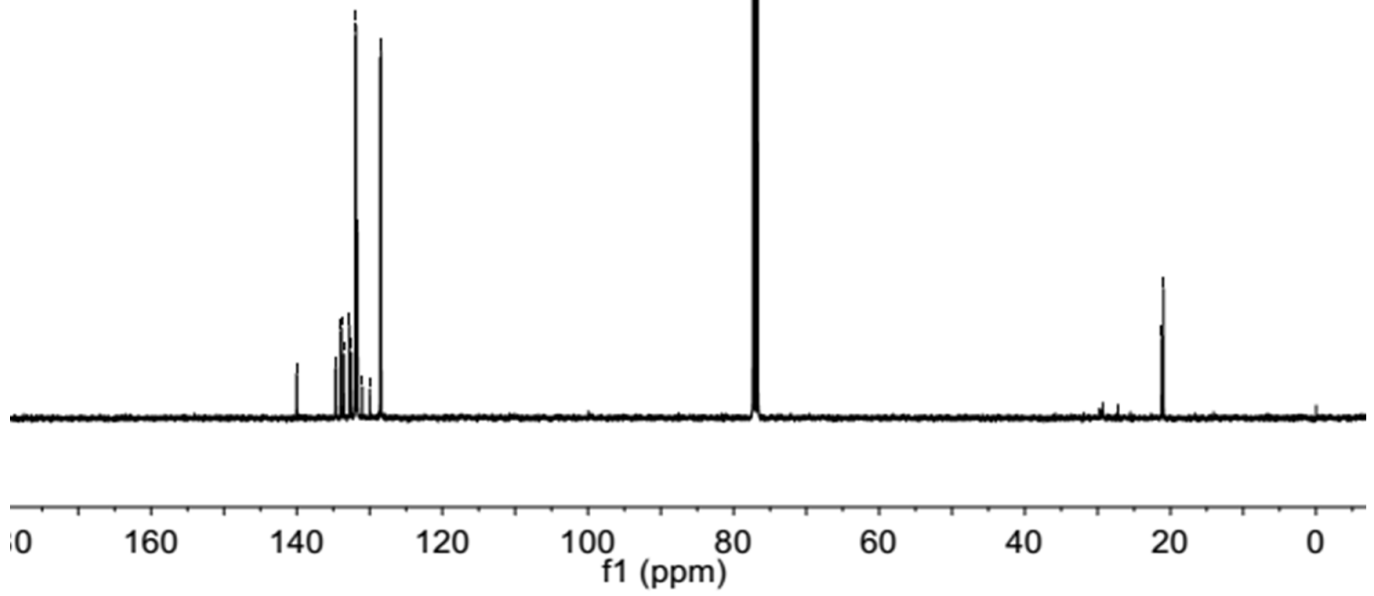



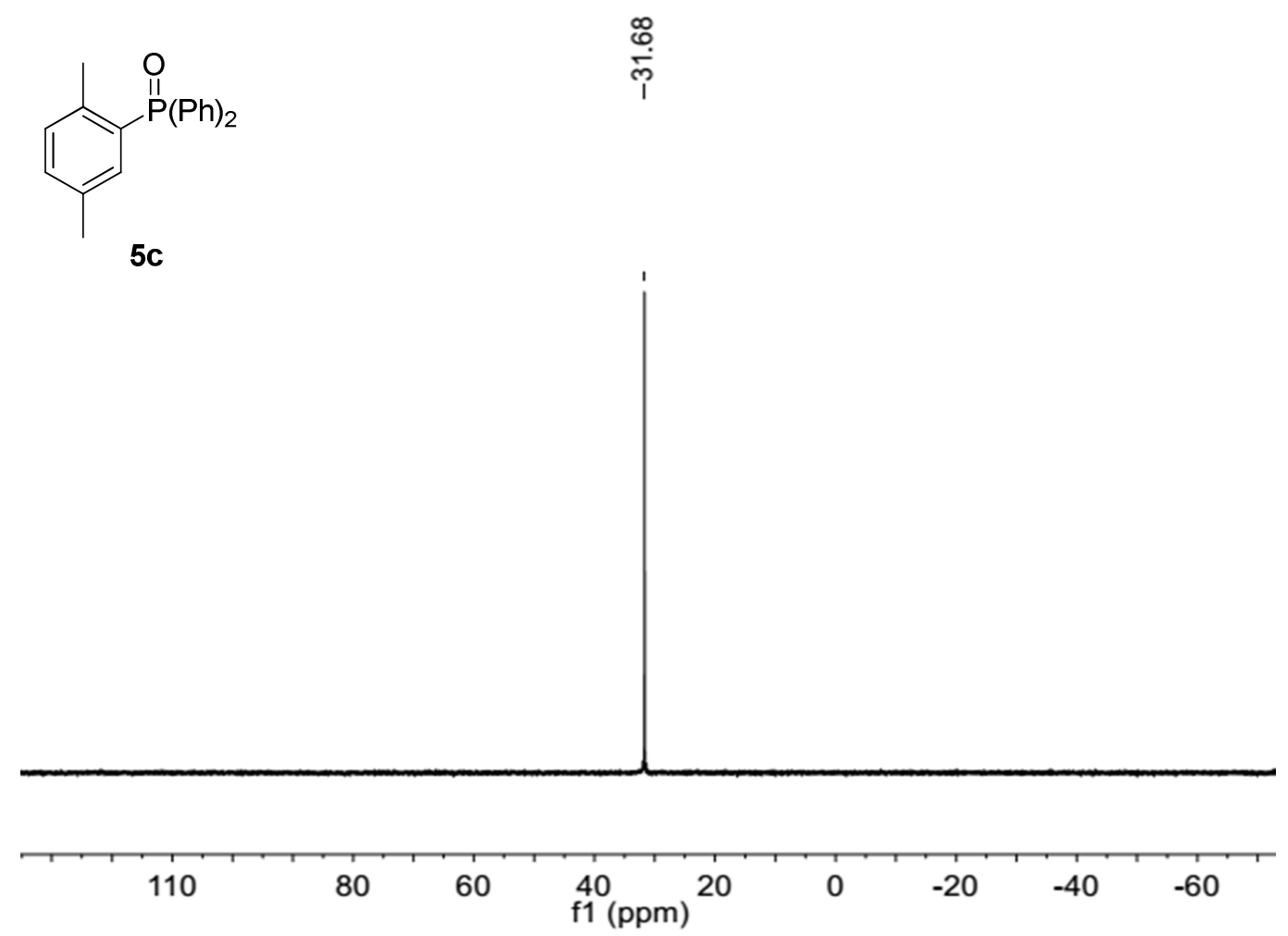

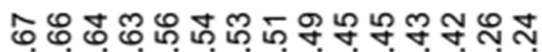

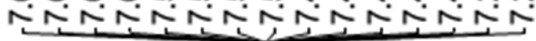

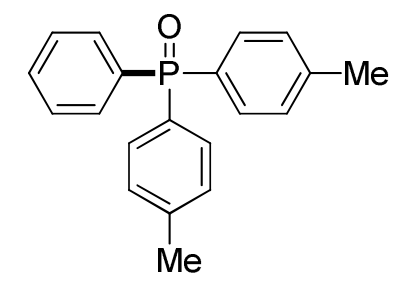

্ָ

$5 d$

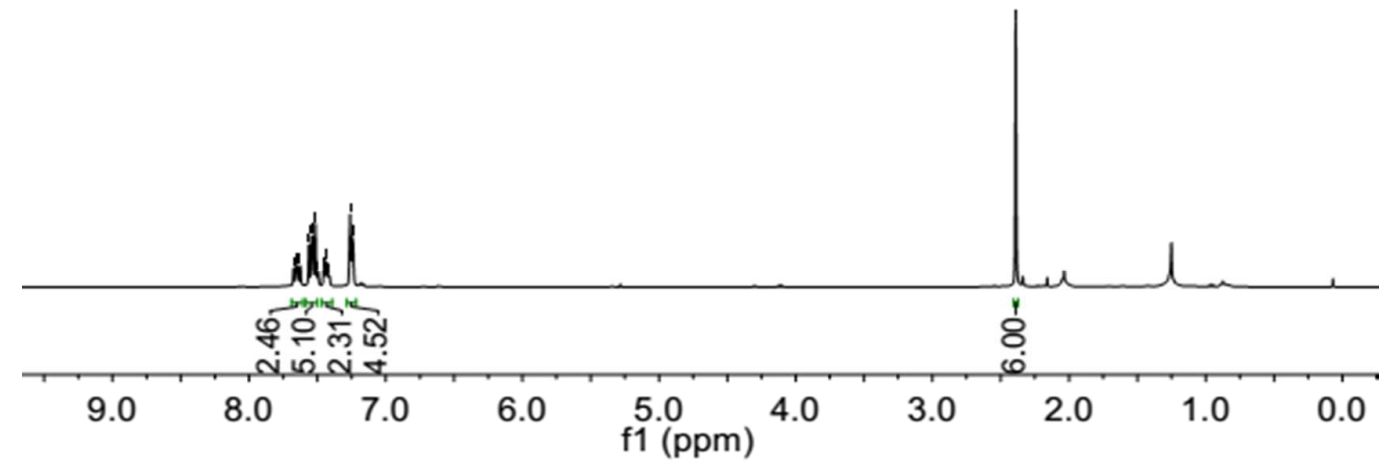



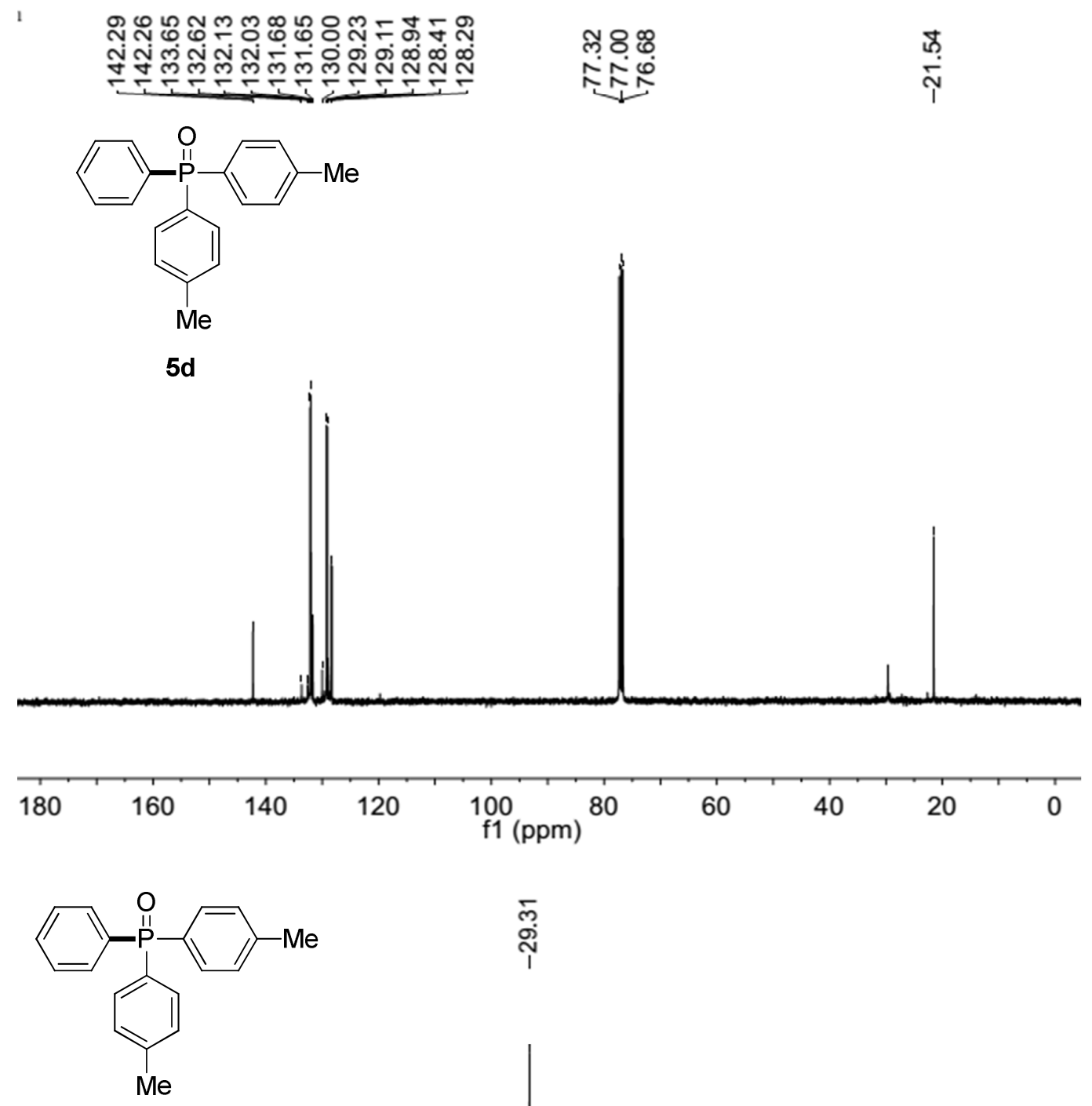

๓্

5d

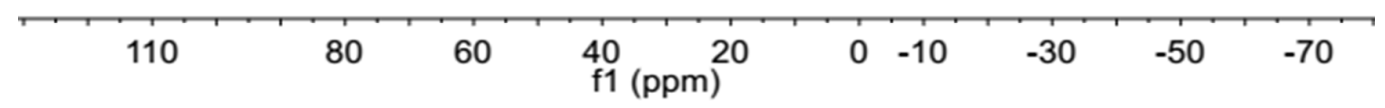



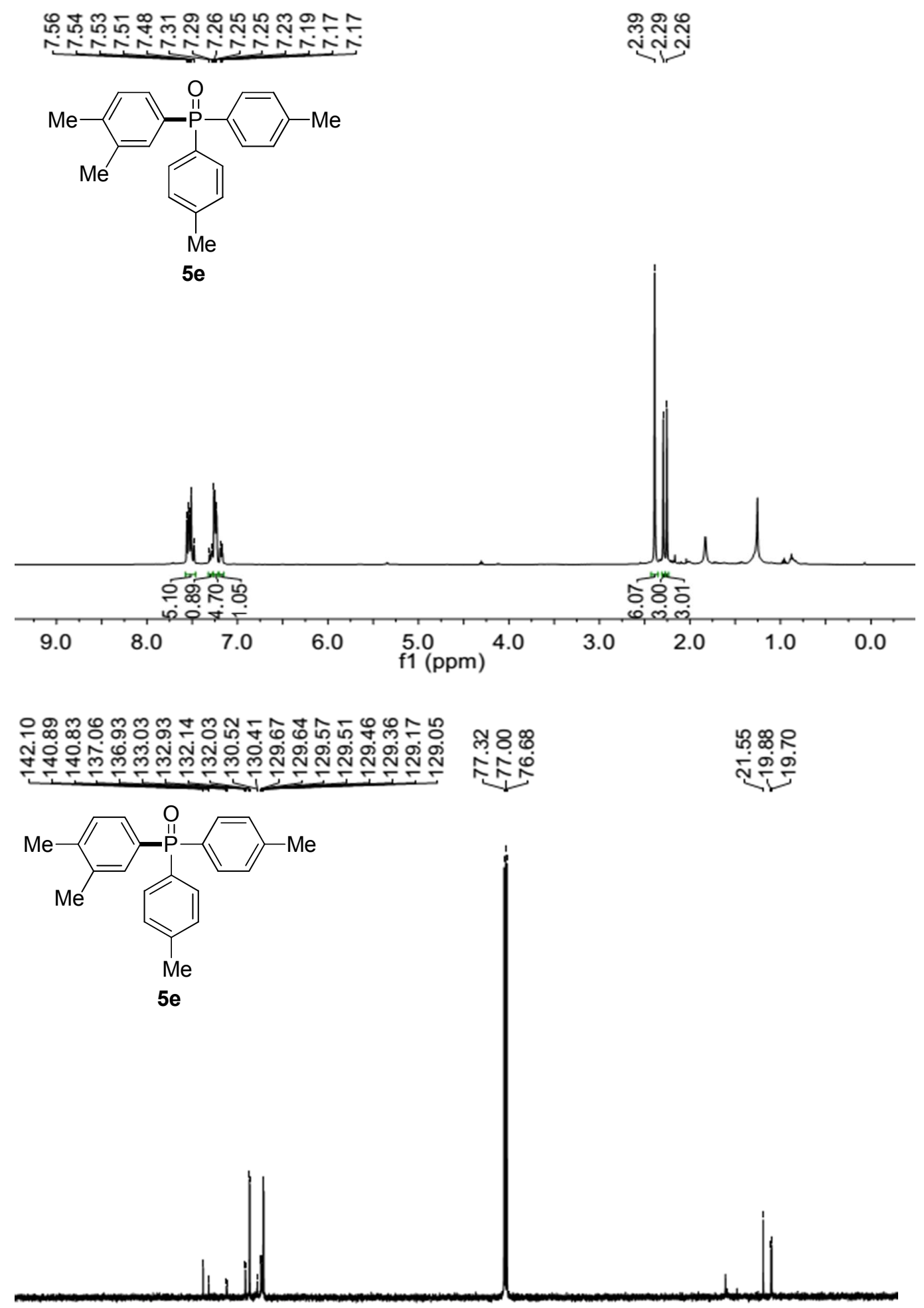

\begin{tabular}{|c|c|c|c|c|c|c|c|}
\hline 180 & 160 & 140 & 120 & $\underset{\mathrm{f} 1(\mathrm{ppm})}{80}$ & 60 & 40 & 20 \\
\hline
\end{tabular}



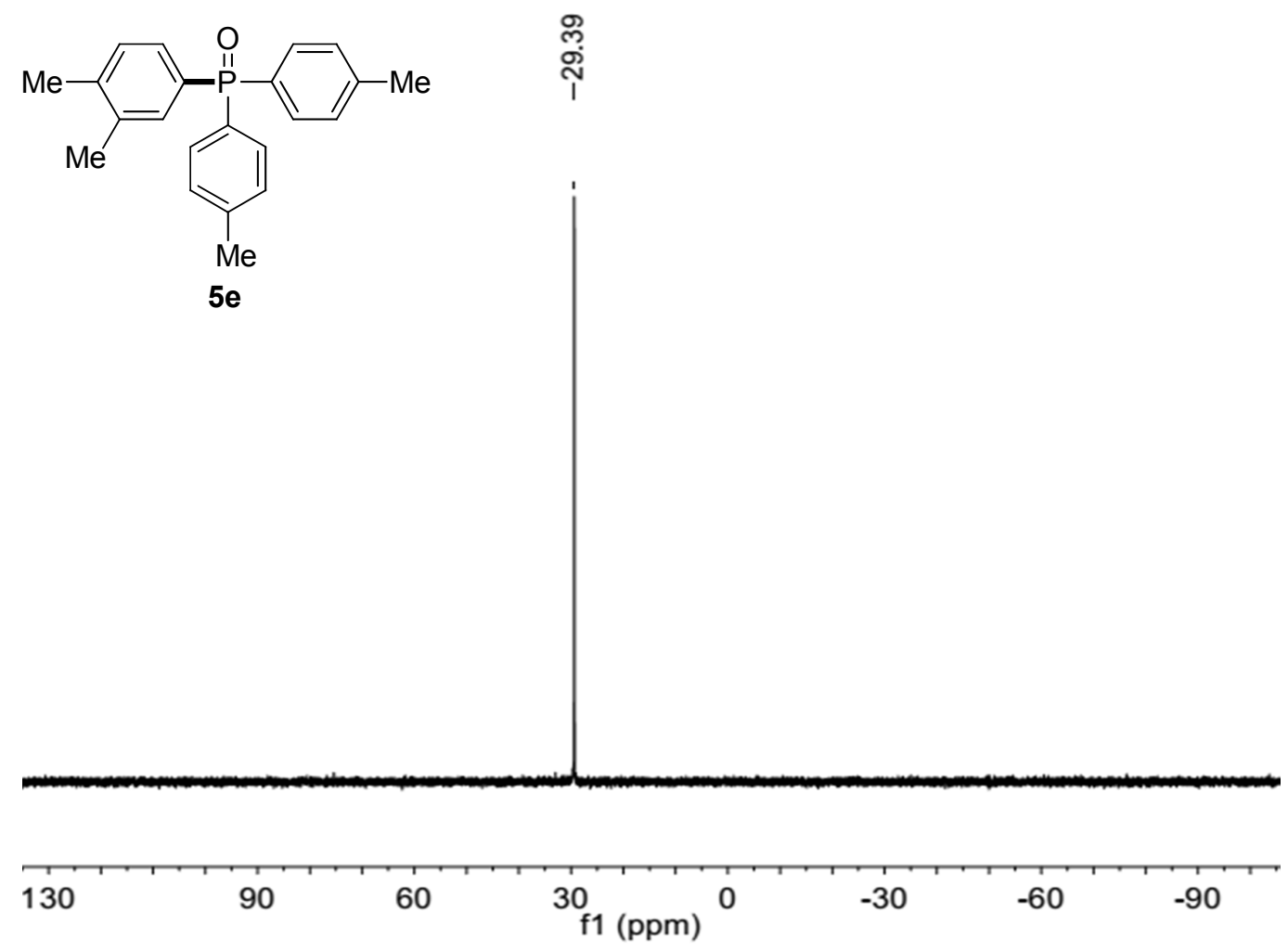

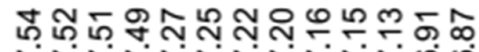

NNNNNNNNNNGO

암유요

ชู
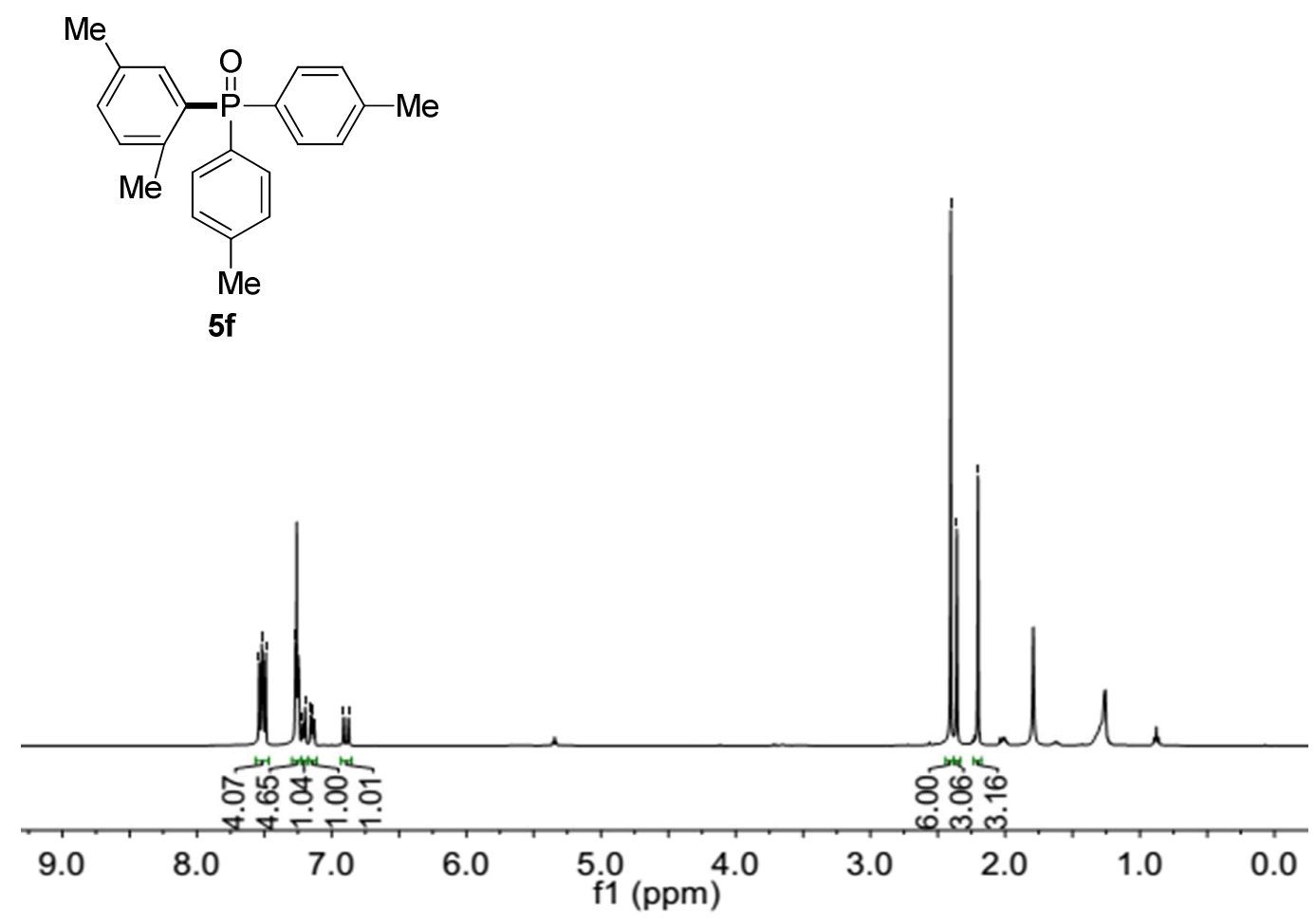


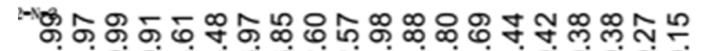

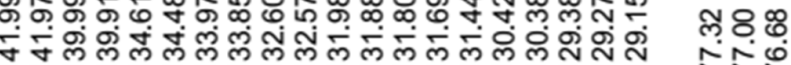

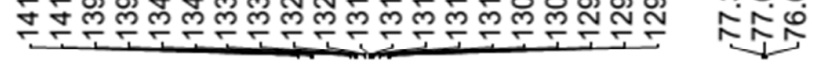

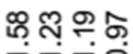

సิํํำ
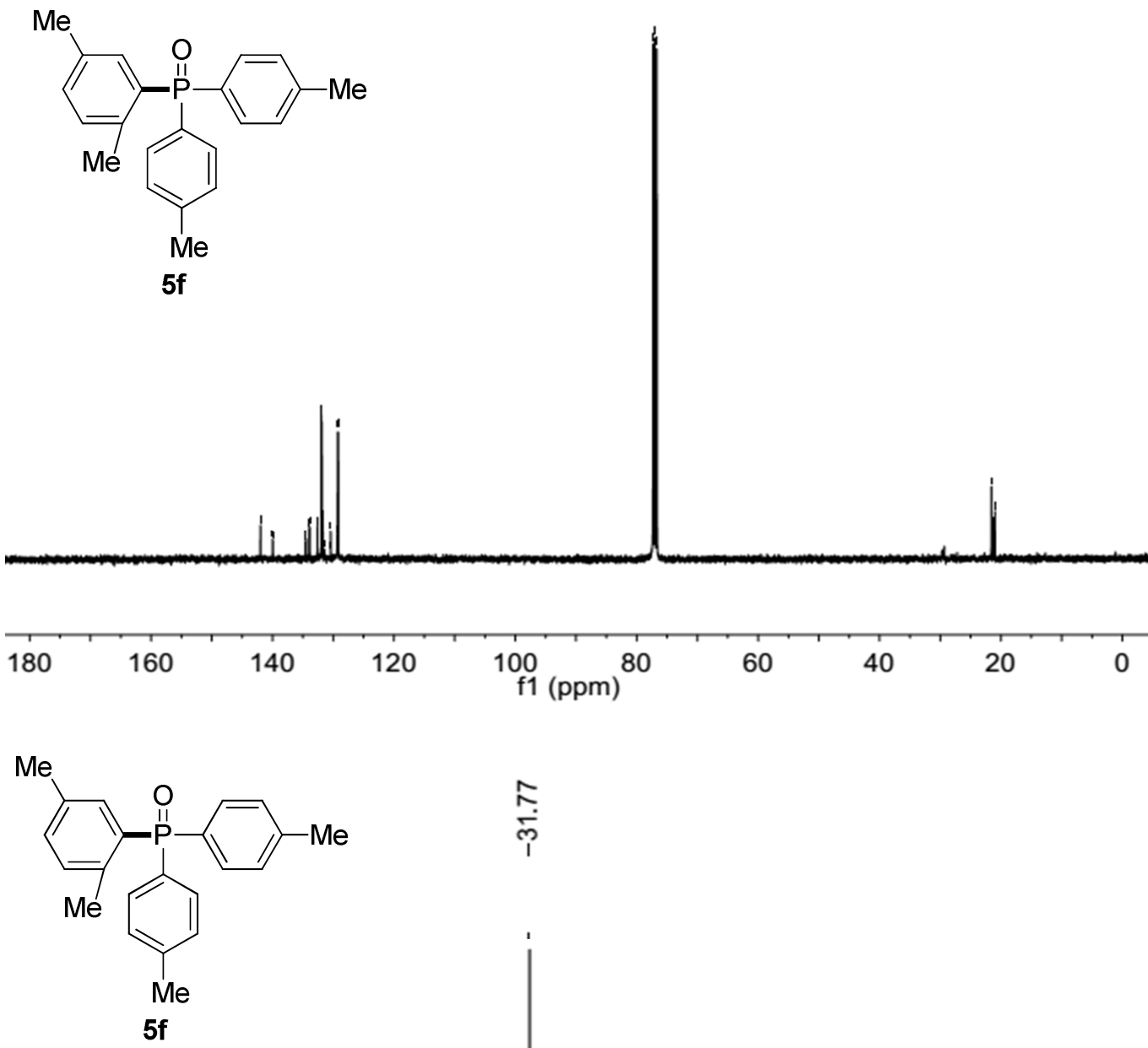

竔

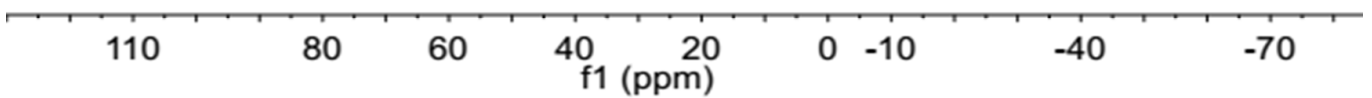


<smiles>Cc1cc(C)cc(P(=O)(c2ccccc2)c2cc(C)cc(C)c2)c1</smiles>

$5 g$

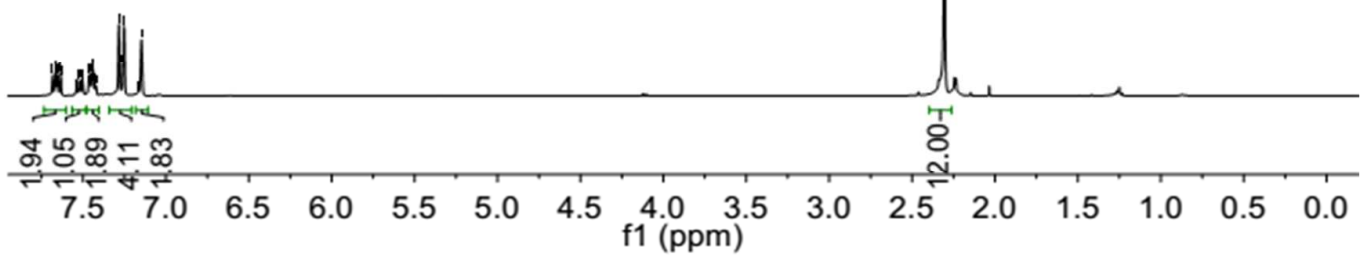

*

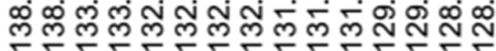

\section{స్ల $8:$}

篎<smiles>Cc1cc(C)cc(P(=O)(c2ccccc2)c2cc(C)c(C#N)c(C)c2)c1</smiles>
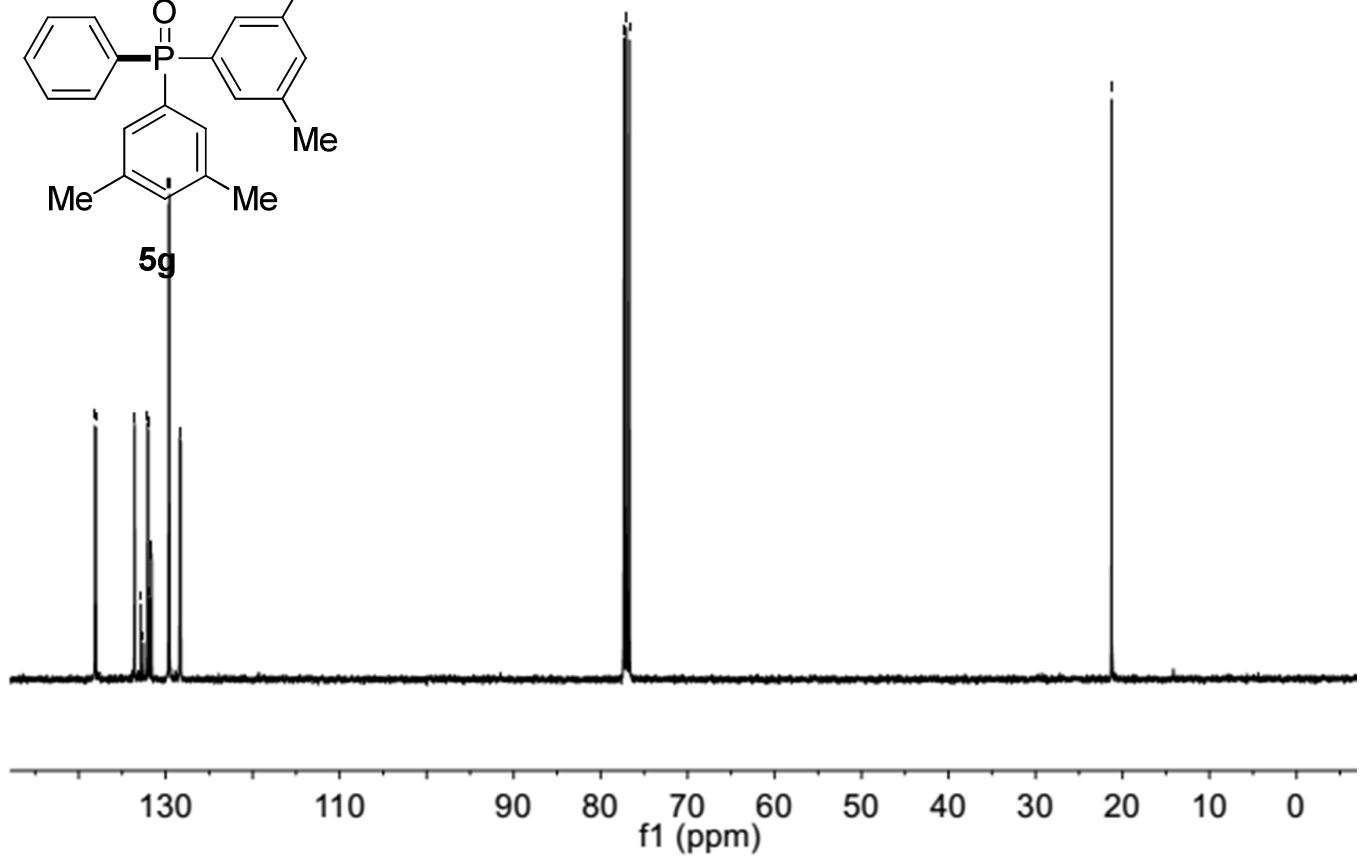


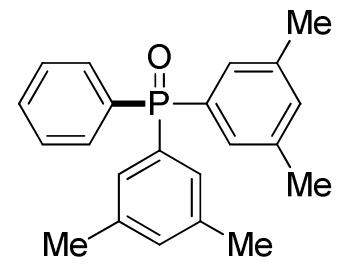

5g

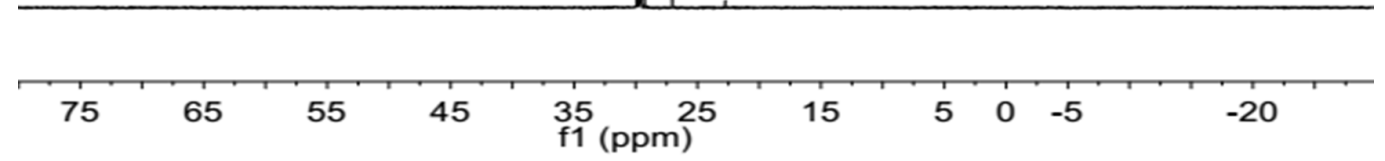

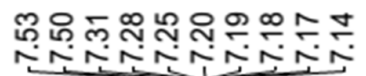

હู่<smiles>Cc1cc(C)cc(P(=O)(c2ccc(C)c(C)c2)c2ccc(C)c(C)c2)c1</smiles>

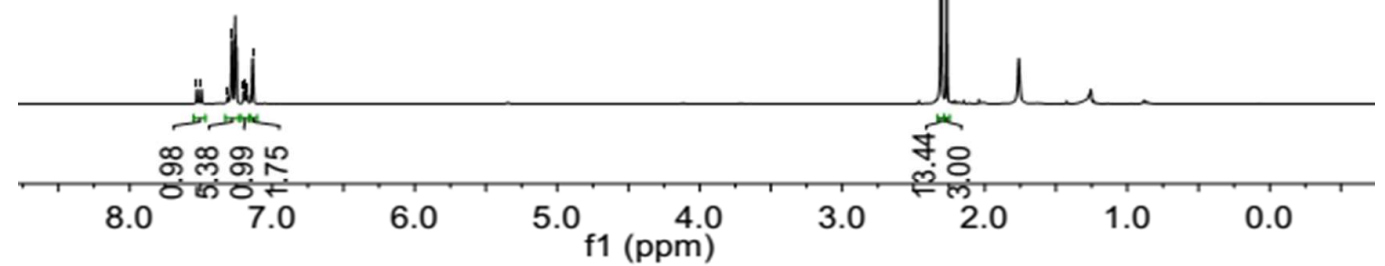


ฟำ

守守

ลิ ฉ

둔<smiles>Cc1ccc(P(=O)(c2cc(C)cc(C)c2)c2cc(C)cc(C)c2)cc1</smiles>

$5 h$
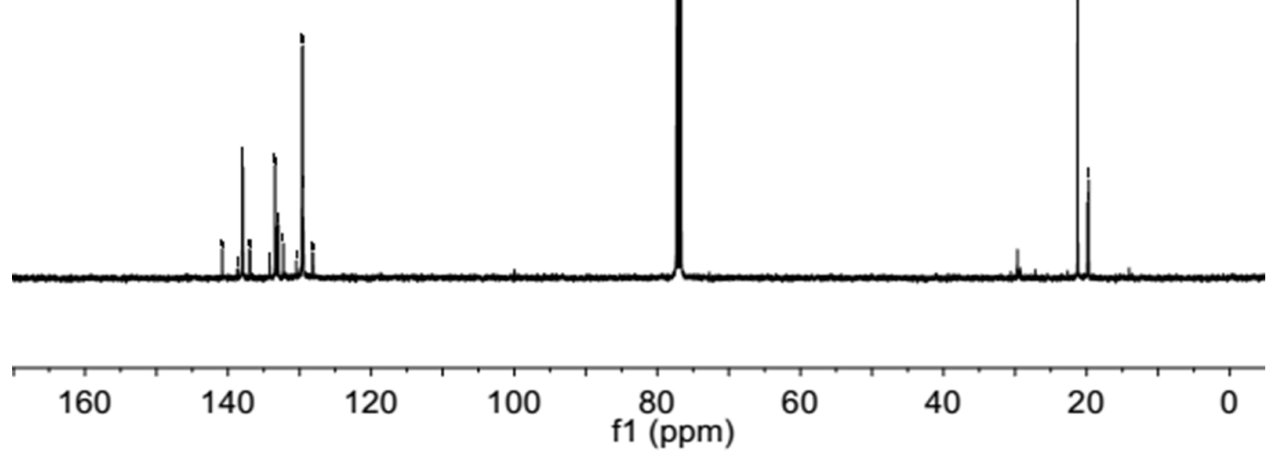<smiles>Cc1cc(C)cc(P(=O)(c2cc(C)cc(C)c2)c2ccc(C)c(C)c2)c1</smiles>

윰

$5 h$

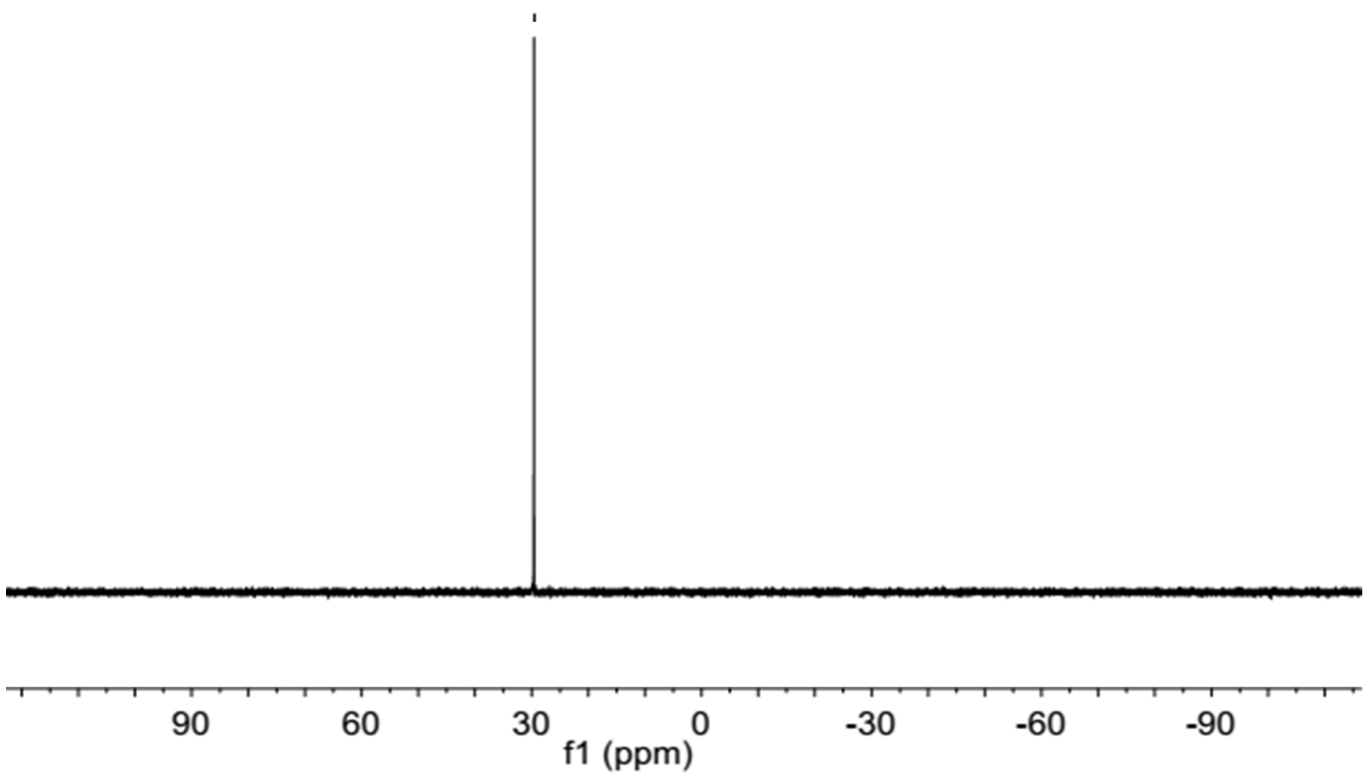




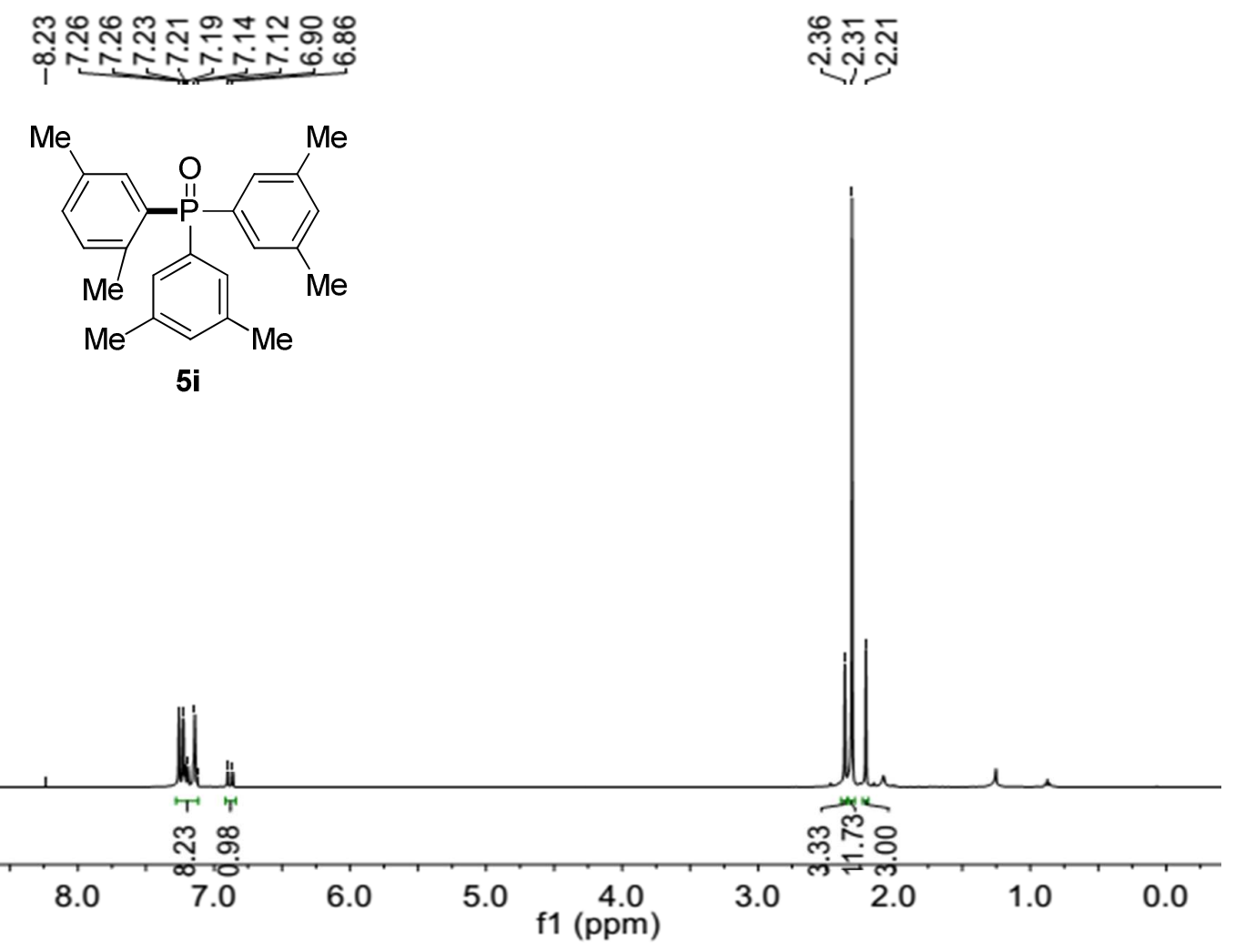

\%

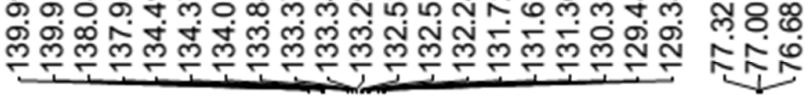

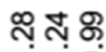

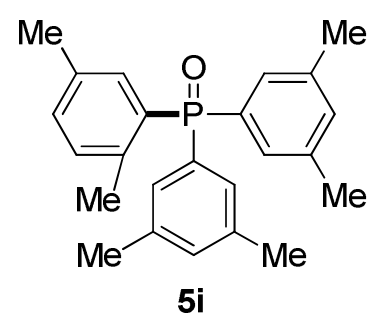

సั่
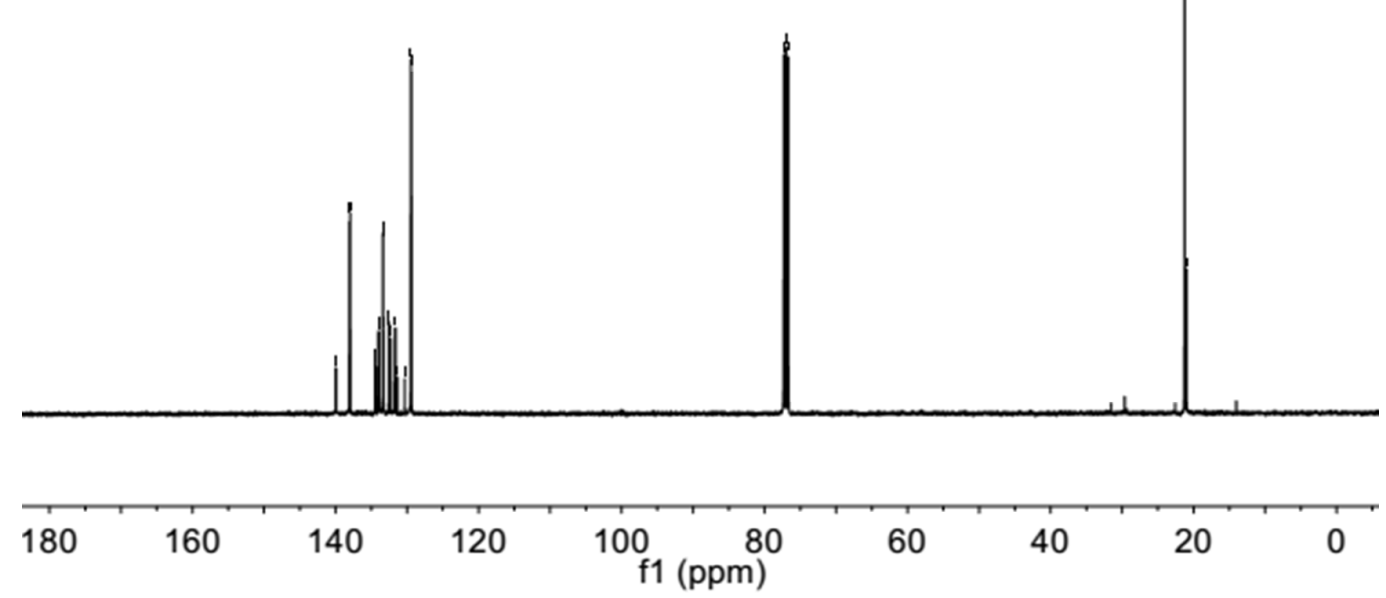


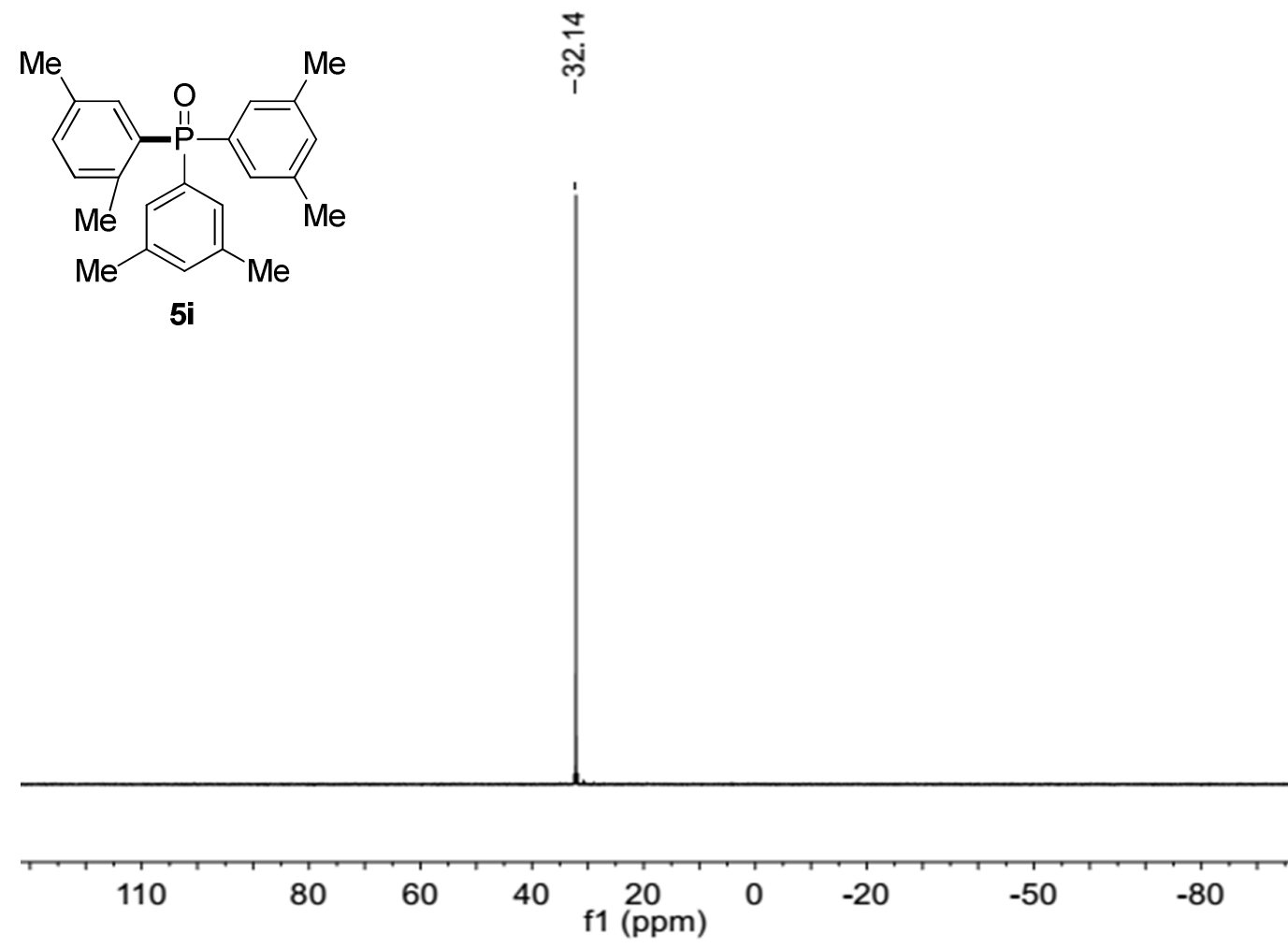

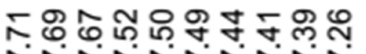

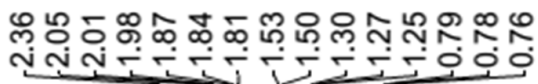

NNNNNNN

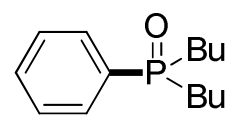

5j

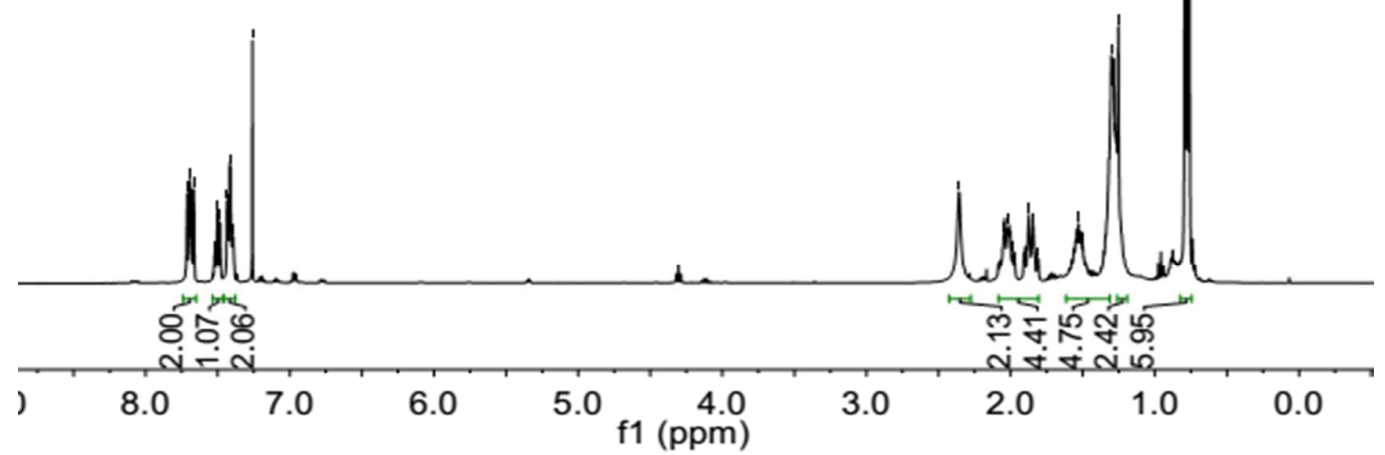




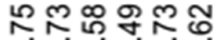

लं

๓ 8 우

NN

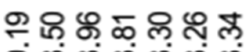

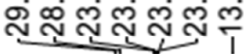

$\longrightarrow{ }_{-\mathrm{Bu}}^{\mathrm{O}}-\mathrm{Bu}$

5j
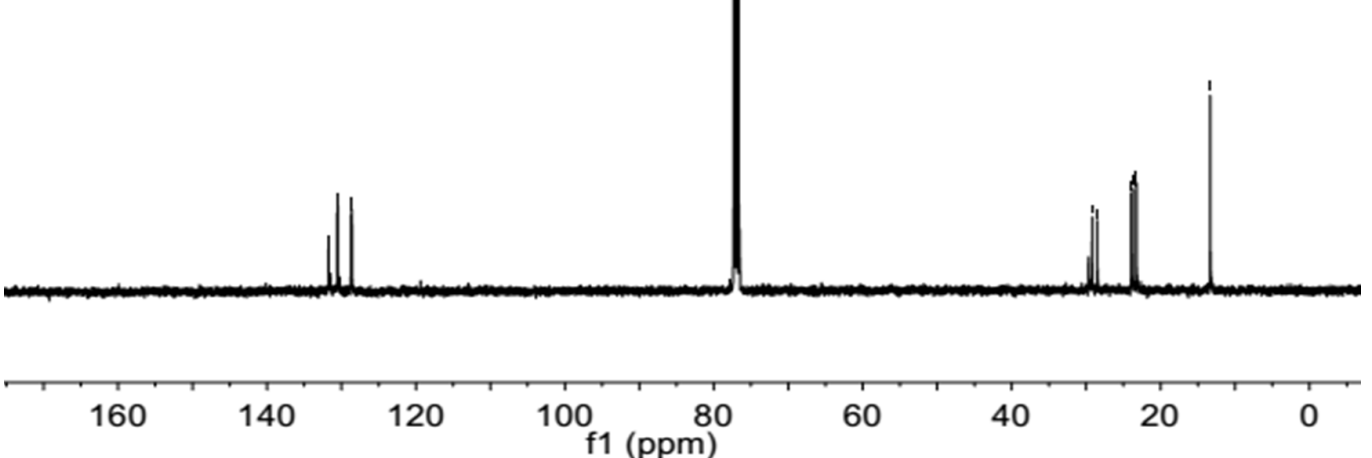

$\longrightarrow P_{-\mathrm{Bu}}^{\mathrm{O}}-\mathrm{Bu}$

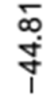

5j

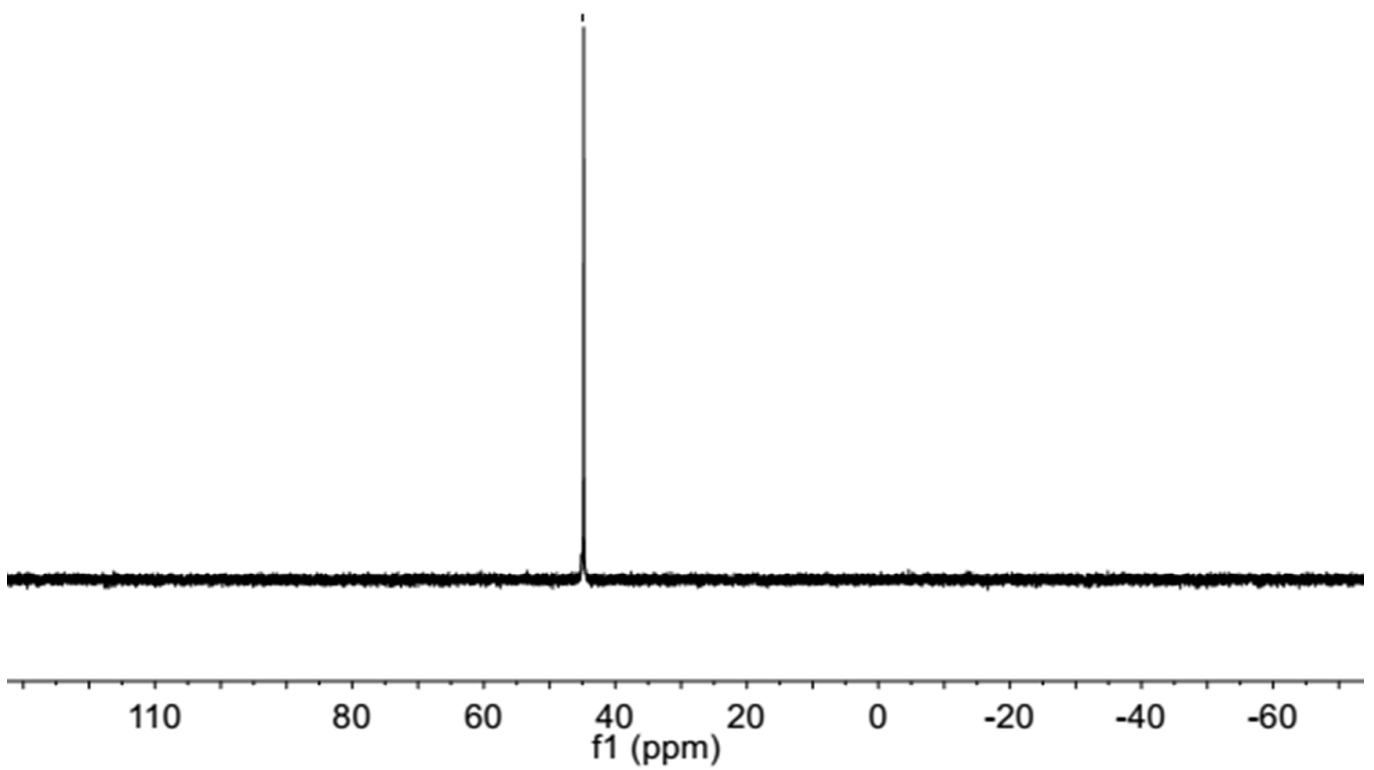




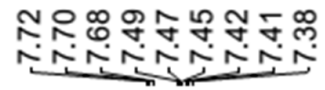

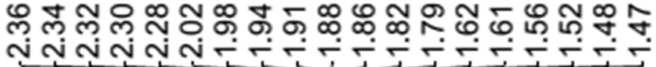

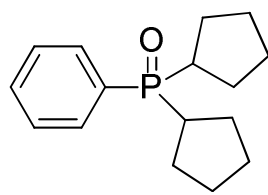

$5 k$

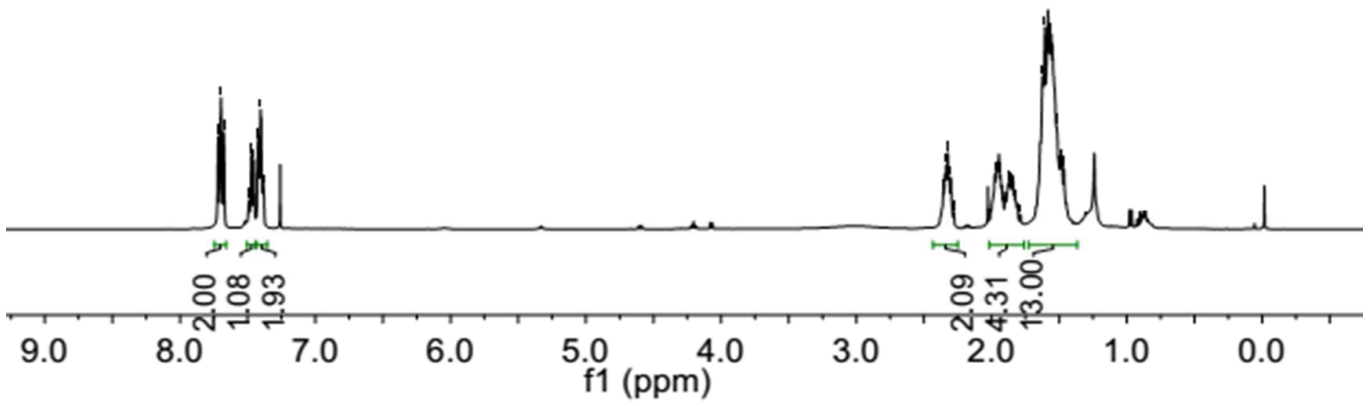

œ

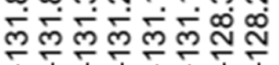

กิ 8 ชุ

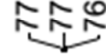

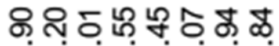

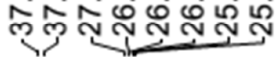

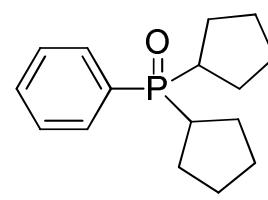

$5 k$

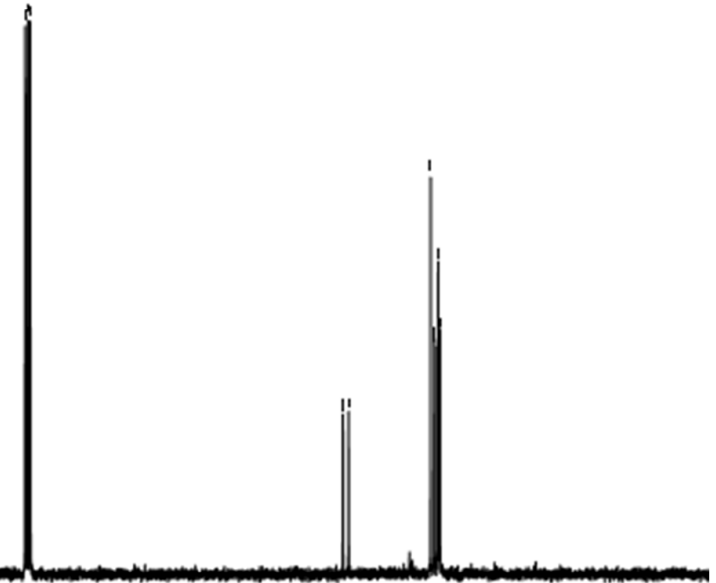




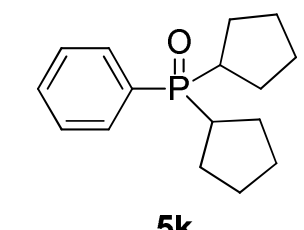

गे
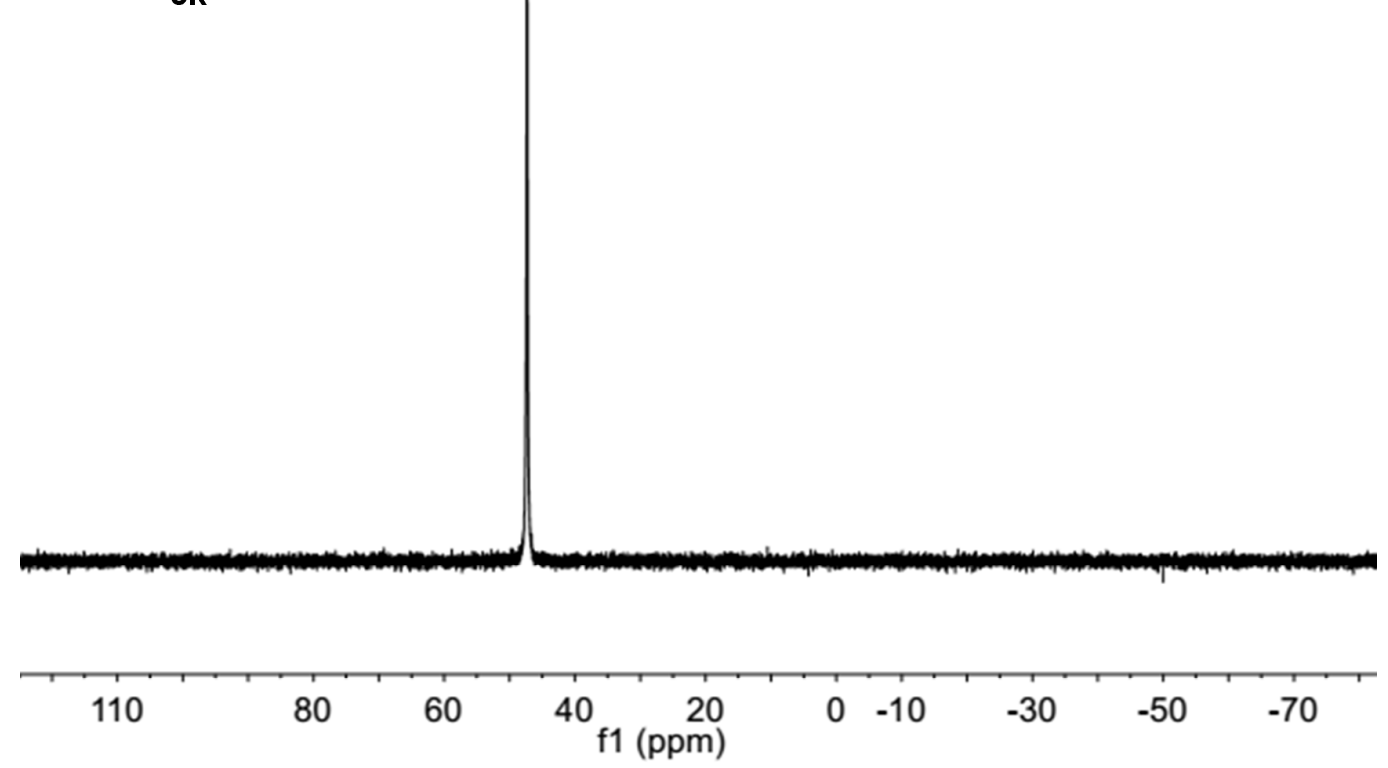

ซ

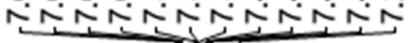<smiles>O=[Pb]([OH2+])c1ccccc1P(=O)(O)c1ccccc1</smiles>

$5 a-d$
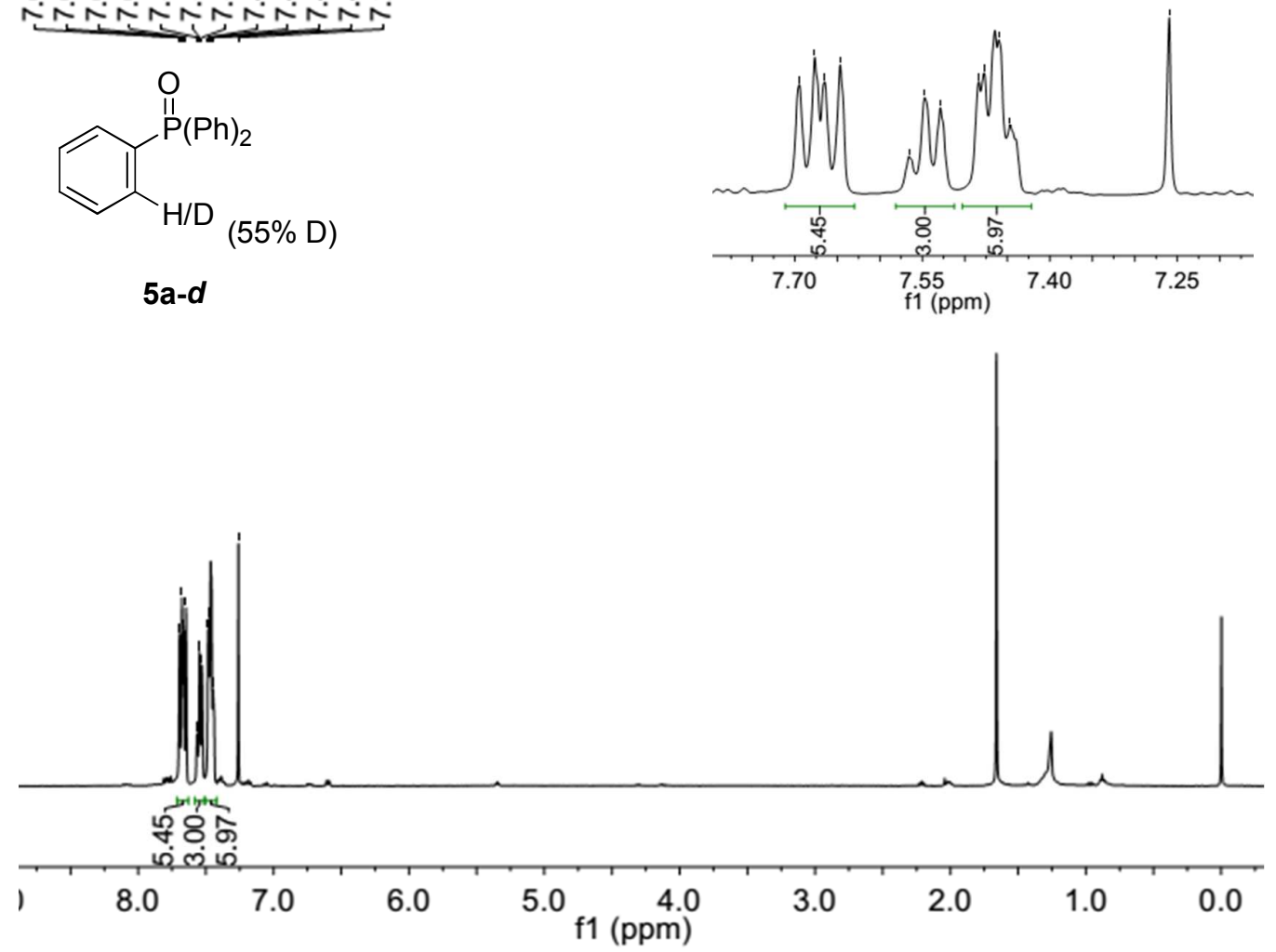